\title{
The linguistic realization of information packaging*
}

ENRIC VALLDUVÍ and

ELISABET ENGDAHL

\section{Abstract}

There is increasing awareness of the large degree of crosslinguistic diversity involved in the structural realization of information packaging (or information structure). Whereas English and many Germanic languages primarily exploit intonation for informational purposes, in other languages, like Catalan, syntax plays the primary role in the realization of information packaging and intonation is reduced to a secondary role. In yet another group of languages the primary structural correlate is morphology. This paper provides a contrastive analysis of the structural properties of information packaging in a number of languages. It also contains a discussion of some basic issues concerning information packaging and identifies a set of information-packaging primitives that are applied to the crosslinguistic facts.

\section{Introduction}

Alternative sentential structures, differing in string order, in intonational structure, or in both, may be used to express the same propositional content. Nevertheless, these sentential structures are not interpretively equivalent in absolute terms, but rather add some extrapropositional contribution to meaning. Several pragmatic factors have been argued to affect sentential form: illocution, implicature and presupposition, empathy, and the cognitive status of discourse referents (familiarity/novelty), among others. This paper focuses on one of them, information packaging, and discusses how information packaging is structurally realized in a sample of languages.

A set of information-packaging primitives that are crosslinguistically sufficient and methodologically useful needs to be identified. This set of primitives should allow us to clearly identify structurally different but 
informationally equivalent sentences in a variety of languages. To this effect, sections 2 and 3 review earlier approaches to information packaging and introduce a comprehensive informational partition that captures the insights of these approaches while circumventing their shortcomings. In section 4 we show how these informational distinctions are structurally manifested in a selection of languages, with an emphasis on English, Catalan, and Germanic. Finally, section 5 contains a discussion of how information packaging interacts with other structural, pragmatic, and semantic factors.

\section{Information packaging}

Information packaging (a.k.a. communicative dimension, psychological articulation) is a structuring of sentences by syntactic, prosodic, or morphological means that arises from the need to meet the communicative demands of a particular context or discourse. In particular, information packaging indicates how information conveyed by linguistic means fits into the (hearer's mental model of the) context or discourse. When communicating a proposition $\phi$, a speaker may realize it by means of different sentential structures according to his/her beliefs about the hearer's knowledge and attentional state with respect to $\phi$. The term "packaging" is due to Chafe (1976):

I have been using the term packaging to refer to the kind of phenomena at issue here, with the idea that they have to do primarily with how the message is sent and only secondarily with the message itself, just as the packaging of toothpaste can affect sales in partial independence of the quality of the toothpaste inside (Chafe 1976: 28).

The following quotes from Clark and Haviland (1977) and Prince (1986) reflect the view of information packaging adopted here:

To ensure reasonably efficient communication, $[. .].[t]$ he speaker tries, to the best of his ability, to make the structure of his utterances congruent with his knowledge of the listener's mental world (Clark and Haviland 1977: 5).

Information in a discourse does not correspond to an unstructured set of propositions; rather, speakers seem to form their utterances so as to structure the information they are attempting to convey, usually or perhaps always in accordance with their beliefs about the hearer: what $\mathrm{s} / \mathrm{he}$ is thought to know, what $\mathrm{s} / \mathrm{he}$ is expected to be thinking about (Prince 1986: 208).

As a first approximation to the effect of information packaging in linguistic structure and interpretation, consider the examples in (1): 
(1) a. Mary hates chocolate.

b. Chocolate Mary hates.

c. Chocolate Mary loves.

Sentences (1a) and (1b) are truth-conditionally equivalent. They differ not in what they say about the world, but in how they say what they say about the world; that is, they differ in the way they are packaged. Compare now (1b) and (1c). Even though they differ in their truth conditions, they nevertheless exude a certain interpretive equivalence. This is a result of the fact that they are packaged in the same way. In other words, (1b) and (1c) differ in what they say about the world, but not in how they say it. In the proposal presented below, each one of the ways in which propositional content is packaged is referred to as an instruction. We will say that each sentence encodes a meaning, expressed as a logical formula $(\phi, \psi, \ldots)$, and an information-packaging instruction (A, B, ...). Thus, (1a) and (1b) encode some meaning $\phi$ and (1c) encodes some meaning $\psi$. Simultaneously, (1a) encodes an instruction of, say, type A, and (1b) and (1c) encode an instruction of type B.

In every language there is an array of sentences that, like (1a) and (1b), differ only in the way they say what they say about the world. These alternatives cannot be used interchangeably in context. Use of particular alternatives is constrained by the current context. This can be empirically confirmed in terms of discourse felicity. For instance, while (1a) is a felicitous answer to the question What does Mary hate?, (1b) is not. The infelicity of $(1 \mathrm{~b})$ is due to the fact that its packaging is not appropriate in this context.

The partition of sentences into focus-ground (also known as commenttopic, rheme-theme, new-given, etc.) plays a central role in information packaging (see Hockett 1958; Kuno 1972; Halliday 1985; Erteschik-Shir 1986; Prince 1986; Rochemont 1986; Ward 1988; among others). There is a wealth of characterizations of focus-ground, but they all share one characteristic: focus-ground divides the sentence into a part that anchors the sentence to the previous discourse or the hearer's "mental world" and an informative part that makes some contribution to the discourse or the hearer's "mental world."

But, how do speakers go about packaging utterances? What are the informational primitives that underlie the diversity in sentential form information packaging is meant to account for? In trying to answer these questions several proposals have been put forward: the terms focus, (back) ground, topic, comment, given, new, theme, and rheme, among others, all refer to proposed informational primitives. In section 2.1. these proposed informational articulations are reviewed. 


\subsection{Two informational articulations}

The differences between the different information-packaging articulations proposed in the literature lie mostly in the way the primitive notions used in each articulation are defined (Appendix A contains a list of proposed articulations with selected references). Despite these individual definitional and conceptual differences, these proposals can be reduced, in terms of their empirical predictions, to two: (a) those that divide the sentence into ground and focus, and (b) those that divide the sentence into topic and comment.

2.1.1. Ground-focus. The ground-focus articulation partitions the sentence into a noninformative, known, or expected part - the ground and an informative, newsy, dominant, or contrary-to-expectation part the focus. Several English instantiations of this partition are illustrated in (2). Here and below, F-labelled brackets $\left.\left({ }_{F}\right]\right)$ are used to delimit the focus (without implying syntactic constituency of any sort), and capital letters indicate the lexical item associated with sentential nuclear stress within the focus:

(2) a. The pipes are [F RUSTY].

b. The pipes [F are RUSTY].

c. [F The PIPES are rusty].

d. [F the PIPES] are rusty.

e. The pipes [F ARE] rusty.

In (2a) the focus is the copular predicate and in (2b) it is the entire VP. In English these two cases are structurally identical. The former is often called a narrow focus and the latter a wide focus. Examples (2c) and (2d) are also structurally identical. As illustrated by (2c), a token uttered by M. Hemingway in W. Allen's Manhattan (1979), sentences may lack a ground altogether, that is, they may consist entirely of informative, new material. Finally, (2e) is an example of narrow focus on the sentential polarity. This type of focus, along the narrow focus on tense, aspect, or any other inflection-related element, is sometimes called verum focus. Narrow focus on the verb is not always a case of verum focus, since the verb proper can be focus as well.

Groundhood and focushood are relational notions (e.g. Jacobs 1984; Prince 1986). What makes the foci in (2) new or informative is not their denotational force per se, but rather the fact that they provide an instantiation to some variable or parameter in an underspecified context. In (2d), for instance, the pipes denotes a hearer-known entity (this is structurally realized through the definite article). Nevertheless, its newness 
comes from the fact that it instantiates a parameter in a context in which it is established that some things are rusty but not which thing or things are rusty.

Even though the sentences in (2) express one and the same meaning, in the sense specified above, they are not interchangeable in any given context. To show this, it is common practice to set up contexts for these sentences by using appropriate questions that take them as answers. In this respect, each one of the sentences in (2) is an answer to a different question or set of questions: ${ }^{1}$

(3) a. What about the pipes? In what condition are they?

The pipes are [F RUSTY].

b. What about the pipes? What's wrong with them?

The pipes [F are RUSTY].

c. Why does the water from the tap come out brown?

[F The PIPES are rusty].

d. I have some rust remover. You have any rusty things?

[F The PIPES] are rusty.

e. I wonder whether the pipes are rusty.

The pipes [F ARE] rusty.

Several distinct characterizations of ground and focus are found in the literature. For Jackendoff (1972: 230) the ground "denote[s] the information in the sentence that is assumed by the speaker to be shared by him and the hearer." For Wilson and Sperber (1979) the ground is the first background entailment. Lambrecht (1987), among others, argues that focus is "the assertion of the utterance," where "assertion" is not a Russellian commitment to the truth of the statement but a reduction of the context set à la Stalnaker (1978). What is not asserted is part of the common ground. Other approaches argue that the ground is not part of a shared common ground but rather what the speaker assumes the hearer knows or believes to be true and is attending to at the time of utterance (cf. Clark and Haviland 1977; Prince 1986).

Rochemont (1986), in an approach to the definition of ground-focus close to that of the modern Prague school, argues that the ground must be c-construable, where c-construable means "having an antecedent in previous discourse." The focus, in contrast, is non c-construable. However, as is well known, there are c-construable foci:

(4) $S_{1}$ : Good morning. I am here to see Mrs. Clinton again.

$\mathrm{S}_{2}$ : Sure, Mr. Smith. Let's see ... One of her assistants will be with you in a second.

$S_{1}$ : I'd like to see [F HER] today. I'm always talking to her assistants. 
The problem with this account is that it fails to divorce the relational newness of foci from newness in the denotational sense relevant for the determination of the accessibility or cognitive status of a discourse referent. C-construability is a cognitive-status notion and groundhood cannot be defined in terms of it. Even though the ground in a particular sentence is likely to have become hearer-known via previous reference in the discourse, it need not, since other sources of hearer-knownness are available (see section 5.1 for more on cognitive status). ${ }^{2}$

Let us remark on some terminological issues. In this article we use the term "focus" in its pragmatic informational sense, namely to indicate that part of the sentence that provides relational new information relative to a given context. However, the term has several uses other than the one intended here. It has been used, as a purely phonological term, to designate intonational prominence in a sentence. Indeed, in many languages, if not all, the informational focus must contain the sentential nuclear stress. However, the informational ground may contain prominent elements as well (Bardovi-Harlig 1983). Furthermore, intonational prominence may be associated not only with information packaging but with other linguistic dimensions as well (e.g. illocution, string-based deaccenting) and may also be a consequence of nonlinguistic effects as well. In semantics, "focus" has been used as a synonym for quantificational nuclear scope. Quantifiers are sometimes analyzed as operating on meanings structured into a nuclear scope or nucleus and a restrictor. The latter provides the domain of quantification for the operator. Informational grounds are excellent candidates for restrictorhood and, therefore, informational foci are often nuclei (cf. "association with focus" in Jackendoff 1972). Nevertheless, since there is no isomorphy between ground-focus and restrictor-nucleus, the terminological distinction is important (see Vallduví and Zacharski 1994 for a discussion of the relationship between informational focus, pitch accent, and semantic nuclei).

The term "focus" (sometimes called "AI-focus") is also used in computational treatments of cognitive status and in (psycho-)linguistic analyses of reference (see e.g. Grosz 1981; Garrod and Sanford 1982; Gundel et al. 1993). According to Sidner (1981), all discourse entities are ranked according to salience in a "focus stack." The "focus" is the most salient discourse entity at a given time point, that is, the one at the top of the focus stack. Referents "in focus" are those hearer-known referents that are in some sense "activated" or "salient" and that can be referred to with a pronominal form. Being in focus in this sense, that is, salience, is a cognitive status and does not relate to newness in the relational sense of ground-focus outlined above (see Hajičová 1987 and Gundel 1994 for 
a discussion of informational focus and salience; Dahl 1976 also recognizes the need to distinguish salience from information update).

Our informational focus has also been called "new" (Halliday 1967, 1985), "NewInfo" (Välimaa-Blum 1988), "rheme" (Firbas 1964; Contreras 1976; Steedman 1991) and "dominant constituent" (ErteschikShir 1973, 1986). Several of these terms are, like "focus," used elsewhere with different meanings. The ground has also been called "background" (Dahl 1974; Chafe 1976), "presupposition" (Chomsky 1971; Jackendoff 1972) "open-proposition" (Prince 1986; Ward 1988), "OldInfo" (Välimaa-Blum 1988), "given" (Halliday 1967, 1985), "theme" (Firbas 1964; Contreras 1976; Steedman 1991), and "topic" (Hajičová 1984; Sgall et al. 1986). "Presupposition" as ground is not the same as classic presupposition (the kind that, for instance, displays constancy under negation [Lakoff 1971]). The pair "given" and "new" are also extensively used to describe nonrelational cognitive status, which is potentially very confusing, since as we saw in (4) an expression may denote a hearergiven referent while simultaneously being relationally new or focal. "Theme-rheme" in Halliday are actually closer to "topic-comment" (see section 2.1.2), not to "theme-rheme" in Firbas and Contreras. "Topic" as a synonym of "ground" is of course different from "topic" as used in the topic-comment articulation. Finally, it should be noted that topic and focus (i.e. ground and focus) in Sgall et al. (1986) are not primitive notions but rather derived from the concepts of contextual boundedness and communicative dynamism.

2.1.2. Topic-comment. A classic description of how the topic-comment articulation divides the sentence is the one found in Hockett (1958: 201): "the most general characteristic of predicative constructions is suggested by the terms 'topic' and 'comment' for their ICs [immediate constituents]: the speaker announces a topic and then says something about it" (1958: 201). The following is a characteristic definition as well: "An entity, E, is the topic of a sentence, $S$, iff in using $S$ the speaker intends to increase the addressee's knowledge about, request information about, or otherwise get the addressee to act with respect to E" (Gundel 1988: 210).

The topic has also been described as a "point of departure for the clause as a message" (Halliday 1967, who uses the term "theme") or as a "reference frame" for the sentence. It is clear that the topic performs the anchoring role to the previous discourse or the hearer's mental world, while the comment is what makes some new contribution. The following examples (from Halliday 1967: 212) illustrate three different topic assign- 
ments on a truth-conditionally equivalent set of sentences (the topic phrase in examples in the remainder of section 2 appears in italics):

(5) a. John saw the play yesterday.

b. Yesterday John saw the play.

c. The play John saw yesterday.

Both Gundel (1974) and Reinhart (1982) note that topic phrases display a characteristic "aboutness" feeling. For instance, each one of the sentences in (5) can be embedded in the frame He said about $x$ that $P$, where $x$ stands for the appropriate topic phrase and $\mathrm{P}$ expresses the comment.

Sentences may be topicless, that is, they may consist entirely of a comment (e.g. Gundel 1988). These are the so-called presentational or news sentences (Schmerling 1976), neutral descriptions (Kuno 1972), or thetic sentences (Kuroda 1972; Sasse 1987). Topicless sentences and allfocus sentences are the same thing. Let us contrast the topic-comment structure in (6a) and the news sentence in (6b):

(6) a. The screen DIED.

b. The SCREEN died.

The structural difference between these two examples is intonational. In the topic-comment structure nuclear stress falls on the predicate, whereas in the topicless structure nuclear stress falls on the subject (in [6a], in addition, a different pitch accent may be associated with the topic). As the examples in (5) suggest, there seems to be a correlation between topichood and lefthand position in the clause. Some authors claim that topics have to be sentence initial (Halliday 1967). Others allow topics in other positions but specify that any phrase encoded in a specific lefthand slot must be interpreted as a topic (Gundel 1988) (we will return to the lefthand placement of topics below).

The use of "topic" is a terminological minefield as well. As noted in section 2.1.1., "topic" is also used as a synonym of ground by various authors. In addition, there exists the notion of discourse topic seen as a proposition or entity a given text or discourse is supposed to be about (cf. Brown and Yule 1983). There is undoubtedly some relationship between discourse topic and the sentential topic in a topic-comment partition, though what this relationship is is less clear. Finally, there is Givón's (1983, 1992) notion of "topicality" (also called "continuity"). In Givón's approach all discourse referents are hierarchically ranked according to topicality. The most continuous one is the "topic." Ironically, the topicality hierarchy of Givon is akin to the notion of focus stack mentioned in section 2.1.1. The AI-focus would be, roughly, the (most continuous) topic for Givón. For an exhaustive survey of the 
different meanings and uses assigned to these terms see Schlobinski and Schutze-Coburn (1992) and Humphreys (1993).

\subsection{Conflating topic-comment and ground-focus}

There is some overlap between topic-comment and ground-focus (e.g. the presentational topicless sentence in [6b] is informationally identical to the all-focus sentence in [2c]). But neither informational articulation is, by itself, capable of capturing all the informational distinctions present in the sentence. In the answers in (7), for instance, the ground-focus partition accounts for the distinction between the focus $a$ shirt and the ground (the rest of the sentence):

(7) a. What about Mary? What did she give to Harry?

She gave [F a SHIRT] to Harry.

b. What about Harry? What did Mary give to him?

To Harry she gave [F a SHIRT].

Without resorting to independent accounts, however, this articulation has nothing to say about the fact that an element of the ground appears in situ in (a), but in a lefthand position in (b), that is, it does not account for the extra informational value of to Harry in (b). Similarly, the topiccomment partition accounts for the lefthand position of the different phrases in (a) and (b), but it cannot offer an explanation of why the comment in the answer in (7a), repeated here in (8a), is different from the comment in the answer in (8b):

(8) a. What about Mary? What did she give to Harry?

She [c gave a SHIRT to Harry.]

b. What about Mary? What did she do?

She [c gave a shirt to HARRY.]

The intonational contrast between (8a), where to Harry is noninformative or nonfocal, and (8b), where to Harry is focal, is reflected by the groundfocus articulation, but not by the topic-comment partition.

It is true that in examples like (9) the two articulations split the sentence in the same way, as indicated in (10) by means of the labelled bracketing notation. For such cases, one articulation would appear to be sufficient:

a. What about John? What does he do?

b. John drinks BEER

a. [T John] [c drinks BEER]

b. [G John] [F drinks BEER] 
But when the same exact string is used in the context shown in (11) (from Dahl 1974: example 3), which triggers a different ground-focus partition, either articulation in isolation is insufficient. The ground-focus and topic-comment segmentations in (12) are nonidentical:

(11) a. What about John? What does he drink?

b. John drinks BEER

a. [r John] [c drinks BEER]

b. [G John drinks] [F BEER]

As a matter of fact, the need for more than just one of these articulations has long been noticed. Halliday $(1967,1985)$ and Dahl (1974) opt for including both topic-comment and ground-focus in the informational description of sentences (Halliday calls the former theme-rheme and the latter given-new). This, however, does not avoid the redundancy that arises in cases where topic-comment and ground-focus make the same structural predictions. In other words, what is required is, in some sense, not one articulation or two articulations, but one and a half articulations. In fact, Välimaa-Blum (1988) does just that. She states that the groundfocus distinction must be complemented with a notion of S-topic, akin to the topic in topic-comment.

Vallduvi (1992) circumvents the insufficiency of the binomial articulations with the introduction of a tripartite hierarchical articulation. This articulation parallels Välimaa-Blum's proposal but integrates all the primitives within one single schema. The trinomial articulation divides sentences into a focus and a ground (as in the ground-focus partition), while the latter is further composed of a link and a tail, as in (13). This tripartite division cuts (9b) and (11b) as in (14a) and (14b), respectively:

(13) $\mathrm{S}=\{$ focus, ground $\}$ ground $=\{$ link, tail $\}$

(14) a. What about John? What does he do?

[G [L John]] [F drinks BEER]

b. What about John? What does he drink?

[G [L John] drinks] [F BEER]

In what follows we adopt this tripartite articulation. Section 3 discusses how each primitive contributes to information packaging. ${ }^{3}$

\section{An instruction-based approach}

Different information packagings are viewed in Vallduví (1992, 1994a) as different instructions for information update. The sentences in (1) in 
section 2 have the same propositional content but encode different instruction types, that is, different ways of indicating how the meaning of the sentence should be "unpacked." Each instruction type - there are four of them - corresponds to a different focus-ground partition. The focus is defined as the actual update potential of a sentence $S$, that is, the only contribution that (according to the speaker) $S$ makes to the information state of the hearer at the time of utterance. Since all sentences have some update potential, they all have a focal segment. The ground, in contrast, is already subsumed by the input information state and acts as an usher for the focus: it indicates how the information update is to be carried out. Sentences have a ground only if the context warrants its use, that is, if the ushering is (thought by the speaker to be) required. As noted, the ground is further divided into link and tail. Link and tail each contribute in their own way to the ushering role of the ground. Links indicate WHERE the focus should go in the input information state: they establish a particular locus of update in the input information state. A tail indicates How the focus fits there: the presence of the tail indicates that the nondefault mode of update is (in the speaker's eyes) required at that point in discourse.

In order to see exactly how the elements in the ground carry out their task, something must be said about the structure of information states. For current purposes, let us view an information state as a filelike data structure (cf. Heim's [1982] files in file change semantics). Files are collections of file cards. Each file card has a number of records or conditions written on it listing attributes and relations about the entity it denotes. The content of these file cards is updated during communication. Information packaging reflects the way the speakers take into account their assumptions about the structure of the hearer's information state in order to optimize information update. Simultaneously, yet independently, the marking of cognitive status (familiarity/novelty) of discourse referents (see section 5.1) is responsible for providing the hearer with instructions for file-card management (very roughly, an indefinite NP instructs the hearer to create a new file card [denotes a novel referent], while a definite NP instructs the hearer to activate a dormant, already existing file card [denotes a familiar referent]). ${ }^{4}$

In this light, links are argued to designate a specific file card in the input file where information update is to be carried out. The term "link" is borrowed from Trávníček, who describes his "theme" as "the sentence element that links up directly with the object of thought, proceeds from it, and opens the sentence thereby" (cited in Firbas 1964: 269). The parallelism between designating a specific locus of update in the input file and linking with the "object of thought" is clear. Similar proposals 
are Reinhart (1982: 24), where it is suggested that links ("topics" for her) "are one of the means available in the language to organize or classify the information exchanged in linguistic communication - they are a signal for how to construct the context set, or under which entries to classify a new proposition" and Kuno (1972), where it is proposed that links should be viewed as "sort keys" to file and access information. ${ }^{5}$

The tail segment encompasses ground material that does not display linklike behavior. As part of the ground, the tail further specifies how the update must be effected. In particular, it indicates that focus is not simply added to the file card designated by the link as a new condition (default mode), but rather that focus must complete or alter a condition that is already there and is designated by the tail (nondefault mode). The ground, both link and tail, performs an "ushering" role for the focus: it guarantees that the update potential of the sentence is "discharged" in the appropriate location (from the speaker's perspective) in the input file. If (the speaker assumes) no usher is needed, a sentence will have no ground. If only some ushering is needed, a sentence may have a link but not a tail, or vice versa.

The four instruction types result from combinations of the primitives in (13). They are illustrated in (15) to (18): a link-focus instruction, (15); a link-focus-tail instruction, (16); an all-focus instruction, (17); and a focus-tail instruction, (18):

(15) Tell me about the people in the White House. Anything I should know?

The president $\left[{ }_{F}\right.$ hates CHOCOLATE].

(16) And what about the president? How does he feel about chocolate? The president ${ }_{F}$ HATES] chocolate.

(17) The president has a weakness. [F He hates CHOCOLATE].

(18) You shouldn't have brought chocolates for the president. [F He HATES] chocolate.

Roughly, link-focus instructions designate a locus of update and indicate that the update is carried out with an addition of a condition on that locus. Sentence (15), for instance, is an instruction to use the file card denoting the president as a locus of update and add a condition there with the property 'hates chocolate'. Link-focus-tail instructions designate a locus of update too, but in addition they point to a given condition and indicate that the update completes or alters that condition in some way. (16) instructs the hearer to search for a condition of the form feelslike-about chocolate on the file card denoting the president and substitute 'hate' for the underspecified predicate. Linkless instructions like those in 
(17) and (18) occur when no locus of update need be designated because the current one is inherited from previous discourse. In a given sentence $S_{n}$, the need for a link is preempted if the locus of update of $S_{n}$ is inherited from $\mathrm{S}_{\mathrm{n}-1}$ (see sections 4.2 and 4.1 for more on this type of all-focus instruction). The pair of sentences (17) and (18) differ, like (15) and (16), in that the former indicates a default mode of update and the latter a nondefault one.

There is another type of all-focus instruction besides the kind illustrated in (17). This occurs when no specific file card is designated as a locus of update, but rather a general-situation file card is used:

(19) So, did anything happen while I was gone?

[F The PRESIDENT called].

In this respect, all-focus utterances also have a ground, namely the time and space information that is either mentioned in the preceding discourse, as in (19), or may be inferred from the contextual setting of the conversation. This type of all-focus sentence corresponds to the topicless neutral descriptions of Kuno (1972) or to thetic judgments in Kuroda (1972). This type of linklessness reflects the intuition that these sentences are not "about" any particular referent (cf. Kuno 1972). ${ }^{6}$

The four instruction types just illustrated systematically encompass all the informational constructions previously described in the literature from the topic-comment, ground-focus, and other perspectives. Appendix B contains a list of instruction types, with Catalan and English instantiations, and their relationship with the informational constructions in earlier proposals. This characterization of ground-focus is independent of how given instruction types are realized in particular languages. In fact, the structural realization of these four instruction types varies from language to language. In section 4 we make a systematic comparison of the possible structural realizations of information packaging in different languages using these basic instruction types. ${ }^{7}$

\section{Possible realizations}

So far we have illustrated the instruction-based approach to information packaging with examples from English. We are convinced, however, that it is necessary to look at how information packaging is realized in other languages in order to get a better understanding of the range of possible realizations.

In this section we will first take a closer look at English, which primarily uses intonation to signal informational status, although there is some 
interaction with syntax. We then turn to Catalan, which provides an instructive contrast with English since the sentence accent falls on the final word of the core clause and the language uses syntactic detachments to move nonfocal material away from this position. In the section on West Germanic languages, we look briefly at German and Dutch, which display similarities with English but which also rely on detachment for some informational marking. Hungarian illustrates another language type, which typically moves focal elements into a designated focus position. We also discuss Turkish, which in some respects resembles Hungarian but on closer inspection is reminiscent of the strategies used in Germanic and Catalan. At the end of this section we give a comparative overview of how instructions are realized in the four major types of languages discussed here.

\subsection{English}

As illustrated in (20) ([2] in section 2.1.1 above), focushood in English is associated with nuclear stress. Focal phrases normally do not undergo any syntactic operations such as movement; that is, they appear in their canonical position. Different ground-focus partitions are structurally encoded by shifting the position of nuclear stress on one invariable syntactic structure:
a. The pipes are [F RUSTY].
b. The pipes [ $F$ are RUSTY].
c. [F The PIPES are rusty].
d. [F The PIPES] are rusty.
e. The pipes [F ARE] rusty.

The pitch accent associated with nuclear stress in English is labelled A accent in Jackendoff (1972). Steedman (1991), adopting Pierrehumbert's (1980) phonology of intonation, identifies $A$ accents with a level high tone $\left(\mathrm{H}^{*}\right)$. The $\mathrm{H}^{*}$ is associated with one particular word within the focus and is generally followed by a falling boundary tone. Thus, the items in caps in (20) are in fact associated with a $\mathrm{H}^{*}$ pitch accent. Strings that are prosodically identical, like (20a) and (20b) or (20c) and (20d), are informationally ambiguous (cf. the notion of "range of permissible focus" in Chomsky 1971). This is perhaps clearer in (21), where the different focus readings allowed by each string are simultaneously indicated:

(21) a. John [ left a note ${ }_{F}$ on the TABLE]].

b. John $\left[F\right.$ left ${ }_{F}$ a NOTE] $]$ on the table. 
Of course, these sentences are ambiguous only when used out of context, since context indicates which focus reading is intended. Phrases like $a$ note and on the table in (21a) and (21b) appear in situ no matter what their informational status. This illustrates the fact that in English both focal and ground phrases may appear in situ. The burden of realization is placed on the intonational dimension.

What about the structural encoding of links? Links have been claimed to be necessarily associated with a lefthand position in the clause, but this is empirically inaccurate. Links may be fronted, but they may appear in situ as well. Let us illustrate the realization of links in English with the exchanges in (22) and (23). The question in these examples induces a (contrastive) link interpretation for the phrases the forks and the knives:

Where can I find the cutlery?

a. The forks are in the CUPBOARD ...

b. but the knives I left in the DRAWER. Where can I find the cutlery?

a. The forks are in the CUPBOARD ...

b. but I left the knives in the DRAWER.

The knives in (22b) does indeed appear in a lefthand position, but in (23b) it appears in its canonical position. The input context for these two sentences is the same and the interpretation obtained from them is the same as well. It is not the case, however, that links in cases like (23b) remain structurally unidentified. The lefthand link in (22b) and the link in situ in (23b) are associated with a particular pitch accent. That the knives in (23b) receives a pitch accent is obvious when we compare it to the phrase the knives in (24), where it is completely deaccented:

What did you do?

I left the knives in the DRAWER.

The accent on the knives in (22b) and (23b) is distinct from the pitch accent that characterizes focus. This link-related pitch accent is dubbed B accent in Jackendoff (1972), and Steedman (1991) defines it as a high tone preceded by a distinctive low level $\left(\mathrm{L}+\mathrm{H}^{*}\right)$. In (22) and (23) we have indicated B-accented items in italics. ${ }^{8}$ Topicalized links in English must always be associated with a $\mathrm{L}+\mathrm{H}^{*}$ tone, so, in some sense, the syntactic marking is, in addition to optional, redundant. Nonsubject links in situ are always realized with a $\mathrm{L}+\mathrm{H}^{*}$ tone as well. The accentual marking of subject links, however, is optional if the link in question is noncontrastive. Contrastive links are always B-accented. ${ }^{9}$

Tails, finally, do not appear to be structurally characterized in any way other than by being typically deaccented. As noted, English tails are free 
to remain in situ. The examples in (25) illustrate this. A narrow-focus reading is intended in both sentences, on beer in (25a) and on loves in (25b). John is a link in both:
a. [l John] loves [ $\mathrm{F}$ BEER] (and Mary loves CIDER).
b. [ John] [F LOVES] beer (but Mary HATES it).

The tails in (25a) and (25b), loves and beer respectively, appear in their in-situ position. It is this characteristic of English tails that allows for the existence of potentially ambiguous structures like those in (21). Notice that (25a), for instance, could also be the structural realization of an instruction where the focus was loves beer. This potential ambiguity extends to the case of subjects as well. A sentence like (26) is potentially ambiguous between a link-focus and a focus-tail interpretation:

John [F LEFT].

The subject John is unaccented. Since, as we noted above, noncontrastive subject links may remain unaccented, John may be either a noncontrastive link, as in the context of a question like How come she's all alone?, or a tail, as in the context of Why didn't she come with John? ${ }^{10}$

There is one English configuration in which foci do not remain in situ but rather appear in a noncanonical slot. This has been called focus preposing, focus topicalization, Y(iddish)-movement, or rhematization. In this configuration the focal element is fronted in a topicalizationlike process, while retaining its association with an $\mathrm{A}$ accent:
a. Did you get wet?
b. [F Bloody SOAKING] I was (Hannay 1991: 134).

The existence of this construction has been analyzed by several syntacticians in the government and binding framework (cf. Rochemont 1986) as suggesting that at a certain level of abstraction ALL foci are fronted in such a way.

It has been argued, however, that focus proposing is not equivalent in its informational import to its nonfronted counterpart. Ward (1988) and Vallduví (1992) defend the position that two sentences like (28a) and (28b) receive different informational interpretations:

(28) a. They named their dog [F FIDO]

b. [F FIDO] they named their dog

Ward shows that in cases like (27b) and (28b) the fronted phrase actually refers to two discourse elements: the first, a set or scale, and the second, a specification of a value or an element in that set or scale. In (27b) the scale is the scale of wetness and the value is bloody soaking; in (28b), the 
set is the set of dog names, probably ordered among them in terms of clichédness, and the value is the extremely clichéd Fido. In these examples the specification of the relevant value is indeed focal and triggers the appropriate structural realization by means of prosody, but the scale this value belongs to is part of the ground. In fact, it is a link, and this is what triggers its realization as a fronted element. Crucially, Fido in (28a) does not give rise to the same interpretation.

Let us, before concluding this section, discuss the informational import of weak proforms. In section 3 sentence (17) was given as an example of an all-focus instruction and was contrasted to (15), a link-focus instruction. We repeat these examples here as (29a) and (29b), respectively:
a. [F He hates CHOCOLATE].
b. The president [F hates CHOCOLATE].

The presence of the pronoun he in (29a) was ignored in describing its informational import. Let us see why. Vallduví (1992) argues that the two sentences in (30) are informationally distinct:
a. John LOVES beer.
b. He LOVES it.

While sentence (30a) is analyzed as having a ground formed by John and beer, $(30 \mathrm{~b})$ is analyzed as an all-focus instruction lacking a ground. To make this distinction between (30a) and (30b) may seem, at first blush, counterintuitive. After all, the two sentences have parallel syntactic and prosodic structures. This is true, but it is also true that there is an important difference between the two: the intonation of (30a) is not the canonical one (compare with the canonical intonation in [31a]), but the intonation of (30b) is (compare with the awkward noncanonical version in [31b]):
a. John loves BEER.
b. ?He loves IT.

One way to account for this contrast is the following. (30a) has a noncanonical contour because there has indeed been a shift of the nuclear stress to the verb to signal that the sentence is an example of verbal narrow focus, thus marking the direct object beer as a tail. In (30b), in contrast, no such intonational operation has been carried out. Nuclear stress appears where it should appear canonically and no item in the sentence is coded as a tail.

Given these considerations, Vallduví (1992) disregards the presence of weak proforms in sentences like (30b) when analyzing instruction types 
and suggests that their presence is due to independent requirements of English grammar, which does not allow for null argument slots (in languages like Catalan the canonical object slot would be empty). The idea that weak proforms do not participate in the construction of instructions is further supported by a comparison of (30b), repeated here as the answer to (32a), and the fragment answer in (32b):

(32) a. How does John feel about beer?

[F He LOVES it].

b. What drink does John love? [F BEER]

Both answers are minimal in the sense that they are the most elliptical of possible answers to their questions (their long versions are John LOVES beer and John loves BEER). Therefore, they are both analyzed as all-focus instructions lacking a ground. The only difference between them is that English disallows sentence fragments of the form loves but allows fragments of the form beer. The weak proforms in (32a) are present only as grammatical place-holders. They are inert as far as information packaging is concerned; therefore, it does not really matter if they appear inside $\left[_{F}\right]$ in our notated examples.

\subsection{Catalan}

First, a few words about Catalan syntax. Contra the traditional view, it is assumed here that Catalan, like other Romance languages, is underlyingly VOS. The VOS hypothesis is defended in Rosselló (1986), Rigau (1988), Bonet (1990), Solà (1992), and Vallduví (1993a) for Catalan and in Adams (1987), Fernández-Soriano (1989), and Contreras 1991, inter alia, for other Romance languages. The relative linear order of the verbal arguments in situ is verb-object-oblique-subject-adjuncts. Catalan is a null-subject language, so subjects need not appear overtly. In contrast, if a verbal complement does not appear within the core clause an appropriate pronominal clitic must be attached to the verb. Arguments may also undergo detachment: left-detachment is a left-adjunction to IP, while right-detachment is a right-adjunction to IP. In any given sentence more than one phrase may be left- or right-detached. If the detached phrase is a verbal complement it must bind a clitic, as expected. The verb itself may also undergo detachment. Heavy NP shift may be the source of other linear orders within the clause. Finally, wh-phrases in wh-questions and other quantificational elements raise to an IP-internal position (Spec of IP) and do not necessarily bind a clitic. ${ }^{11}$ 
Information packaging in Catalan is structurally realized primarily through syntax. As in English, an item within the focus (the rightmost one) is marked with nuclear stress. However, the association of nuclear stress and focushood is attained only through the mediation of syntax. Consider the sentences (33), where one or more arguments are left- and right-detached: ${ }^{12}$

a. El Joan ${ }_{1}\left[F\right.$ va deixar una nota damunt la TAULA $t_{1}$ ]

b. El Joan ${ }_{1}\left[\mathrm{hi}_{2}\right.$ va deixar una NOTA $\left.t_{2} t_{1}\right]$, damunt la taula ${ }_{2}$.

c. El Joan ${ }_{1}\left[{ }_{F} l_{3}{ }^{\prime} h_{2}\right.$ va DEIXAR $\left.t_{3} t_{2} t_{1}\right]$, una nota ${ }_{3}$, Joan obj.loc 3s-pst-leave a note damunt la taula . $_{2}$.

on the table

'John left a note on the table.'

Sentence (33a) is a typical link-focus instruction, where the link is the subject. This sentence may be an answer to the question What did Joan $d o$ ? As expected, nuclear stress falls on the rightmost item within the focus: on taula 'table'. In sentence (33b) part of the predicate is part of the ground as well: the locative phrase damunt la taula 'on the table' is nonfocal. This sentence is felicitious, for instance, in (the Catalan equivalent of ) a context like (34), which requires the locative to be nonfocal:

(34) $S_{1}$ : [narrating] Then, after lunch I laid out all the gifts on the table.

$\mathrm{S}_{2}$ : [interrupting] Oh, by the way, John had left a NOTE on the table. Did you see it?

Again, the A accent falls on the rightmost item within the focus, in this case nota 'note'. Finally, in (33c), as indicated by the bracket notation, all verbal arguments are interpreted as ground. The $A$ accent falls on the only accentable item available within the focus.

The ground phrases in each of the sentences in (33) do not appear in situ; rather, they appear in detachment slots that are external to the core clause. What is going on is that the association of $\mathrm{A}$ accent and focus is attained not by a change in intonational phrasing or a displacement of the pitch accent, but by means of a syntactic operation that removes those elements that must not be interpreted as focal from within the "scope" of the A accent. In (33a) the ground subject is removed from its clause-final base position by means of left-detachment, in (33b) both the subject and the locative are, and in (33c) the object is too. The detachment status of these ground phrases is evidenced by the fact that they must bind a clitic within the core clause (the presence of the clitic 
is illicit when arguments are in situ) and by a number of other diagnostics (linear-order effects, placement of clause-peripheral particles, etc.).

These examples illustrate the fact that in Catalan all and only the overt (nonweak) phrases within the core clause correspond to the focus of the sentence. Ground elements may not remain within the core clause and focal elements may not be detached away from it (Vallduví 1992, 1993a). This pattern is illustrated by the following contextualized sentences. Example (35) shows that, as expected, a direct object in situ is not felicitous in a context where the required focus is verb + locative. Example (36) shows that the appearance of an object in situ is illegitimate even when the focus is only the locative phrase. Finally, sentence (37) illustrates the fact that a focal element cannot be detached:

(35) a. Què en fareu, del ganivet?

'What will you do with the knife?'

b. \#[F Ficarem el ganivet al CALAIX]. 1p-fut-put the knife in.the drawer 'We'll put the knife in the drawer.'

c. [ ${ }_{F} \mathrm{El}_{1}$ ficarem al CALAIX]. obj

'We'll put it in the drawer.'

(36) a. On el ficareu, el ganivet?

'Where will you put the knife?'

b. \#Ficarem el ganivet $[F$ al CALAIX].

1p-fut-put the knife in.the drawer

'We'll put the knife in the drawer.'

c. [F Al CALAIX].

'In the drawer.'

(37) a. On és, el ganivet?

'Where's the knife?'

b. [ $\mathrm{El}_{1}$ vaig ficar $\mathrm{e}_{1}$ al CALAIX]. obj 1s-pst-put in.the drawer

'I put it in the drawer.'

c. \#L $\mathrm{L}_{1} \mathrm{hi}_{2}$ vaig FICAR $\mathrm{e}_{1} \mathrm{t}_{2}$, al calaix ${ }_{2}$.

obj.loc

d. \#Al calaix ${ }_{2} l_{1}{ }^{\prime} h i_{2}$ vaig FICAR $e_{1} t_{2}$.

As expected, in examples of all-focus instructions, no sentence element is detached. Even the subject remains in its base postverbal slot:

(38) [F Deu estar rovellada la CANONADA]. 3s-must be-inf rusty the pipe

'The PIPES must be rusty.' 
It is clear, then, that ground elements are detached. However, nothing has been said so far about the informational import of the directionality of the detachments. The contrast between left- and right-detachment serves to distinguish between the two elements that constitute the ground: left-detached phrases are links, while right-detached ground phrases are tails. In other words, in Catalan links must be left-detached and tails must be right-detached.

The difference between left-detachment and right-detachment becomes evident in contexts that induce the use of contrastive links (see section 4.1). Let us use the same context we used for English examples (22) and (23). The items that in English are necessarily associated with a B-accent are in Catalan necessarily left-detached. Sentence (39b) is the only felicitous continuation to (39a). Here the use of right-detachment for els ganivets 'the knives' is infelicitous and so is an answer with the object in situ. This is shown in (39d) and (39c), respectively:

(39) a. On són, els coberts?

'Where's the cutlery?'

Les forquilles són a l'armari, però ...

'The forks are in the cupboard, but ...'

b. ... els ganivets els $_{1}$ vaig ficar $t_{1}$ al CALAIX. the knives obj 1s-pst-put in the drawer

c. \#... vaig ficar els ganivets al CALAIX.

d. \#... els $s_{1}$ vaig ficar $t_{1}$ al CALAIX, els ganivets ${ }_{1}$.

'... the knives I put in the drawer.'

Also, the directionality of detachment in Catalan teases apart the ambiguity behind unaccented full subjects in English. As noted in reference to (26) in section 4.1, English unaccented subjects can be either tails or noncontrastive links. In Catalan, as expected, tail subjects appear rightdetached, while (noncontrastive) links are left-detached:

Why didn't she come with John?

a. [F Se'n va ANAR], el Joan.

b. \#El Joan [F se'n va ANAR].

the John refl.loc 3s-pst-leave

'John left.'

How come she's all alone?

a. El Joan [F se'n va ANAR].

b. \#[F Se'n va ANAR], el Joan.

'John left.'

Contrastive links and noncontrastive links are encoded alike. Link contrast arises when some salient opposition exists between two file cards 
that have been chosen as loci of update in adjacent sentences. Remember that if a sentence $S_{n}$ shares its locus of update with $S_{n-1}, S_{n}$ need not have a link. Therefore, use of a link in two adjacent sentences will always imply a change in locus of update from $S_{n-1}$ to $S_{n}$ and, under the right circumstances, a contrast between the two loci of update involved. Link contrast is particularly evident in cases of so-called topic switch (or switch reference). This is illustrated in (42):

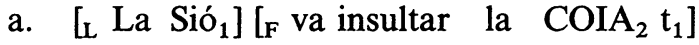

$$
\begin{aligned}
& \text { the Sió 3s-pst-insult the Coia }
\end{aligned}
$$

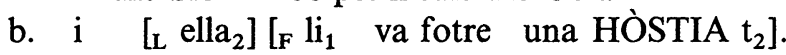

$$
\begin{aligned}
& \text { and she iobj 3s-pst-do a blow } \\
& \text { 'Sió }{ }_{1} \text { insulted Coia }{ }_{2} \text { and she } 2 \text { hit HER }{ }_{1} \text {.' }
\end{aligned}
$$

Sentence (42a) contains a link that designates the file card for Sió as a locus of update. Let us call this file card $\mathrm{fc}_{1}$. Sentence (42b) also contains a link. The mere fact that both these adjacent sentences encode links implies a change of locus of update. Therefore, the locus of update for (42b) cannot be $\mathrm{fc}_{1}$ but rather $\mathrm{fc}_{2}$. The link NP in (42b) is only a (strong) pronoun that, a priori, can refer to either Sió or Coia. But since we know $\mathrm{fc}_{1}$ is Sió, we also know that $\mathrm{fc}_{2}$ is not Sió. The only other candidate for the resolution of the pronoun is Coia.

In section 4.2 we presented arguments that weak proforms do not participate in the construction of instructions. A variant of $(42 \mathrm{~b})$ with a weak pronominal subject would be an all-focus instruction that does not contain a link. The prediction is that, in such a case, there is no change of locus of update, and, therefore, no obligatory switch-reference effect. The prediction is borne out. In Catalan weak pronominal subjects have no phonological matrix. The sequence in (43) consists of a link-focus instruction followed by an all-focus instruction:

$$
\begin{aligned}
& \left.\left.{ }_{\mathrm{L}}^{\mathrm{La}} \mathrm{LSió}_{1}\right]_{\mathrm{F}} \text { va insultar la COIA } \mathrm{t}_{1}\right]_{\text {. [F }} \mathrm{Li} \text { va fotre una HÒSTIA]. } \\
& \text { 'Sió insulted Coia. She hit her.' }
\end{aligned}
$$

This means that the locus of update for both the first and second sentences is the file card specified by the first sentence, namely $\mathrm{fc}_{1}$. Even though we know that $\mathrm{fc}_{1}$ is Sió, this is not sufficient to determine the referent of the null subject in the second sentence. Sió could be the referent of either the subject or the complement. Thus, the second sentence in (43) remains ambiguous. The lack of a link in the second sentence suggests that $\mathrm{fc}_{1}$ has been inherited as a locus of update but does not force coreference for either the subject or the object.

The same is true in English. In English, however, strong and weak subject pronouns are not distinguished by having or not having a phono- 
logical matrix, but rather by being stressed or unstressed (and the ensuing phonological attrition the latter undergo). The English analogue of Catalan (43) is (44):
a. [L $A n n$ ] [F hugged SUE].
b. [F She would forever be GRATEFUL to her.]
c. [l $S h e]$ [F would forever be GRATEFUL to her.]

Sentence (44b) does not designate a new locus of update $\mathrm{fc}_{2}$. Rather, it inherits $\mathrm{fc}_{1}$ from (44a). She in (44b) may refer back to Ann or to Sue. If the subject in the second sentence is realized as a B-accented strong pronoun (i.e. a link), as in (44c), this pronoun designates a new locus of update and, therefore, we have a switch-reference effect. ${ }^{13}$

One additional grammatical contrast between Catalan and English that has effects on the realization of ground-focus concerns the inflectional node of the sentence. English possesses accentable auxiliary elements that realize, at least, tense and polarity. In cases of verum focus where the focus is an inflectional element, the linguistic expression that is associated with intonational focus marking is the auxiliary (e.g. do, have, be, negation). Catalan lacks separate accentable auxiliary elements: there is no do support, and negation manifests itself as a phonological clitic. As a result, cases of verum focus are realized through the verb rather than any auxiliary elements. This is shown in (45) to (47). In (45) the focus is the verb proper, in (46) the focus is tense, and in (47) the focus is polarity. All three sentences are realized in identical fashion with an A-accent on the verb itself:

(45) No cal que hi insisteixis. $\mathrm{L}^{\prime} \mathrm{amo}_{2}\left[_{\mathrm{F}} \mathrm{el}_{1}\right.$ no 3s-need that loc 2s-insist the.boss obj REBUTJARÀ $t_{1} t_{2}$, ] el projecte ${ }_{1}$. 3s-fut-reject the project 'You needn't insist. The boss will REJECT the project.'

(46) Encara no l'ha rebutjat pro, però $\left[\mathrm{F}\right.$ ja $\mathrm{el}_{1}$ yet no obj 3s-pst-reject but prt obj REBUTJARÄ $\mathrm{e}_{1}$ pro.]

3s-fut-reject

'He hasn't rejected it, but he WILL (reject it).'

(47) $S_{1}$ : Segur que el rebutja sense ni mirar-se'l ... 'I'm sure he'll reject it without even looking at it.'

$\mathrm{S}_{2}$ : Estigues tranquilla, que [F no $\mathrm{el}_{1}$ REBUTJARÀ $\mathrm{e}_{1}$ pro.] 2s-imp-be calm that no obj 3s-fut-reject 'Don't worry. He will NOT reject it.' 
In English, judging from the English translations given to these examples, the situation is slightly different. Only in (45), where the focus is the verb proper, is the A accent realized on the verb. In contrast, (46), where the focus is tense, the A accent falls on the auxiliary that carries that tense. Similarly, in (47), where negation is the focus, the focal accent may be realized on the negative element.

\subsection{West Germanic}

This section discusses some issues concerning the realization of information packaging in Dutch and German. The two languages behave very much alike. West Germanic is like English in that it has a "malleable" intonational structure and in that it allows for strings that are informationally ambiguous when out of context. The following examples are adapted from Féry (1992). Examples (48) and (49) illustrate the readings of a string with nuclear stress on the direct object in German and Dutch respectively. Nuclear stress on the immediately preverbal object position is the default in West Germanic. As in (21), the three possible informational readings in these sentences are superimposed. Each reading corresponds to one of the questions in (50): the narrowest reading is an answer to $(50 \mathrm{a})$, the widest reading is an answer to $(50 \mathrm{c})$, and the intermediate reading is an answer to (50b):

(48) Karl hat ${ }_{F}$ dem Kind $\left[_{F}[F\right.$ das $B U C H]$ geschenkt]].

'Karl gave the book to the child.'

(49) Karel heeft $\left[_{F}\right.$ het kind $\left[_{F}\left[_{F}\right.\right.$ het BOEK] gegeven]].

'Karl gave the book to the child.'

(50) a. What did Karl give to the child?

b. What did Karl do for the child?

c. What did Karl do?

In contrast, a string with nuclear stress on the indirect object allows only a narrow-focus reading. The association of nuclear stress and focus is attained by shifting the former to the left. This is shown in (51) for German and (52a) for Dutch:

(51) Who did Karl give the book to?

Karl hat [F dem KIND] das Buch geschenkt.

'Karl gave the book to the child.'

(52) Who did Karl give the book to?

a. Karel heeft [F het KIND] het boek gegeven.

b. Karel heeft het boek [F aan het KIND] gegeven. 
Alternatively, the indirect object may appear next to the verb and associate with nuclear stress by default, without resorting to an intonational shift, as in (52b). The two sentences in (52) are informationally equivalent. The contrast in linear order between (52a) and (52b) is analogous to the contrast between shifted and nonshifted datives in English. The string (52b) is felicitous not only in the context indicated by the question in (52), but also in a context modelled by the question What did Karl do with the book? In this context, the focus is the string formed by the indirect object and the verb:

(53) What did Karl do with the book?

Karel heeft het boek [F aan het KIND gegeven.]

The same string-plus-contour cannot be used to encode a VP-focus sentence, that is, it cannot answer question (50c). ${ }^{14}$

Nuclear stress may also be associated with the subject of the clause. As in English, certain sentences are ambiguous between an all-focus interpretation and a narrow-focus interpretation on the subject. The sentences in (54b) are the German pair and the sentences in (55) their Dutch equivalents:

(54) a. What's happened?

[F GORBATSCHOW ist verhaftet worden].

b. Who has been arrested?

[F GORBATSCHOW] ist verhaftet worden.

'GORBACHEV has been arrested.'

(55) a. What's happened?

[F GORBATSJOV is gearresteerd].

b. Who has been arrested?

[F GORBATSJOV] is gearresteerd.

'GORBACHEV has been arrested.'

Féry identifies the particular pitch accent associated with focushood (at least in declaratives) in German as a bitonal falling accent $\left(\mathrm{H}^{*} \mathrm{~L}\right)$. As noted in section 4.1, in English the focal accent is a level high tone $\left(\mathrm{H}^{*}\right)$. Since this $\mathrm{H}^{*}$ is always followed by a falling boundary tone, these two tones are analogous.

As far as links are concerned, Féry states that in German they require a pitch accent as well. This requirement is illustrated with a subject in (56a) and a topicalized element in (56b):

(56) a. What about the president?

Der Präsident [F wird GEWÄHLT].

'The president's ELECTED.' 
b. What about sleeping? Did any of you get any sleep?

Geschlafen [F hat KEINER von uns].

'As for sleeping, NONE of us slept.'

The pitch accent associated with linkhood, Féry observes, may be either a rising tone $\left(\mathrm{L}^{*} \mathrm{H}\right)$ or a falling tone $\left(\mathrm{H}^{*} \mathrm{~L}\right)$. If the former is used, the contour for German link-focus sentences parallels the contour found in English link-focus sentences: $\mathrm{L}^{*} \mathrm{H} \ldots \mathrm{H}^{*} \mathrm{~L}$ for German, $\mathrm{L}+\mathrm{H}^{*} \ldots \mathrm{H}^{*}$ (L\%) for English. This contour has been dubbed the "hat pattern" by Cohen and 't Hart (1967). In contrast, if a falling tone is used instead, there is actually no phonological difference between the focal pitch accent and the link pitch accent. In this event, the link accent on präsident in (56a) is identical to the focus accent on präsident in (57).

What's going on?

[F Der PRÄSIDENT wird gewählt].

'The PRESIDENT'S (being) elected.'

However, sentences like (57) do not contain a second pitch accent on the predicate of the sentence. This tells the link accent apart from the focus accent, since, whenever an $\left(\mathrm{H}^{*} \mathrm{~L}\right)$ accent is used to realize linkhood, there always exists a second $\left(H^{*} L\right)$ accent to realize focushood. Furthermore, given that the second pitch accent is not downstepped with respect to the former, subjects in experiments still perceive the focal one as more prominent (there may be other effects [e.g. duration] as well).

Dutch also seems to possess the two accent types. It sides with German as well in being able to use either type of pitch accent for the realization of links. As in English, links in West Germanic may be fronted or may be left in situ. This is illustrated with Dutch. These examples are parallel to the English examples in (22) and (23):

De vorken zijn in de KAST ...

'The forks are in the cupboard ...'
a. ... maar de messen liet ik in de LA.
'... but the knives I left in the drawer.'
b. ... maar ik liet de messen in de LA.
'... but I left the knives in the drawer.'

West Germanic, however, uses an additional strategy to realize linkhood: the configuration called "contrastive dislocation" (cf. Zaenen 1984). Contrastive dislocation is, like topicalization, a fronting operation. It differs from the latter, however, in that it binds a pronominal that appears in a lefthand slot as well, but to the right of the contrastivedislocated phrase. Let us illustrate this configuration with a Dutch exam- 
ple. Sentence (59a) contains a contrastive-dislocated link, while (59b) illustrates a topicalized link. The link phrase is de vijf laatste films van Godard 'Godard's last five films' ([a] and [b] are from Zaenen 1984):
a. $\quad{ }_{L}$ De vijf laatste films van Godard $]_{1}$ die $_{1}$ heeft Jan the five last movies of Godard that has Jan gezien.
seen
'Godard's last five films Jan has seen.'
b. [L De vijf laatste films van Godard] heeft Jan gezien.
c. $*_{[F}$ De vijf laatste films van GODARD $]_{1}$ die $_{1}$ heeft Jan gezien.

These two sentences appear to be informationally equivalent. Contrastive dislocation, as shown in (59c), is impossible where the dislocated constituent is focus rather than link..$^{15}$

\subsection{Hungarian and Turkish}

Let us next turn to a fourth language type that contrasts with both the Catalan type and the English/Germanic type. The structural realization of ground-focus relationships involves syntactic strategies, as in Catalan, but, in contrast to this language, these syntactic strategies do not operate on ground elements (they remove the ground FROM a default focal slot) but on focal elements (they move foci To a default focal slot). Hungarian is a language of this type (see Kiss 1981; Horvath 1986; Puskás 1992; inter alia).

Horvath (1986: 91-92) provides the examples in (60). Hungarian is arguably a VO language, so in (60a) the object a földrengéstöl 'the earthquake' appears in situ, where it cannot be realized with focal prominence. In order to be realized as a focus the object must be placed in a position left-adjacent to the verb, as in $(60 \mathrm{~b})$ :
a. *Attila félt [F a FÖLDRENGÉSTŐL.] Attila 3s-pst-fear the earthquake.from 'Attila feared [F the EARTHQUAKE].'
b. Attila [F a FÖLDRENGÉSTÖL] félt.

The same applies to other focused arguments: they appear in this specialized preverbal slot. This immediately preverbal slot is called the "focus position" by Hungarian syntacticians (see Brody 1990). Focushood triggers the movement of an argument to the focus position. Ground elements may appear postverbally or in a lefthand position that precedes the focus 
position. Ground elements that appear prefocally are associated with a link interpretation.

Besides foci, other elements may appear in the focus position: wh-words in wh-questions and a class of elements that includes verb particles, some quasi-incorporated complements, and some adverbs (cf. Puskás 1992). Some of these elements are shown in (61) and (62). The (a) examples show the default position of these elements. The (b) examples show they cannot normally appear postverbally. Finally, the (c) examples show they can appear postverbally if the focus position is filled by a real focus (examples from Puskás 1992: 8) (grammaticality judgments are Puskás's).

a. ELaludt a gyerek.

prt.3s-pst-sleep the child-nom

'The child fell asleep.'

b. *Aludt el a gyerek.

c. KÉSÖN aludt el a gyerek. late 'It was late the child fell asleep.'

(62) a. LASSAN olvas ez a gyerek. slowly 3s-read this the child-nom 'The child reads slowly.'

b. *Olvas lassan ez a gyerek.

c. SZÁNDÉKOSAN olvas lassan ez a gyerek. on purpose

'It is on purpose that this child reads slowly.'

The apparent complementary distribution of real foci and these particles and adverbs has been taken to suggest they are occupying the same slot.

One question that remains unclear in the literature on Hungarian used as a source here is whether the foci that occupy the focus position are necessarily narrow foci or whether, on the contrary, they may be just the accented item within a wider focus, giving rise to informationally ambiguous strings like the ones found in Germanic and discussed in sections 4.1 and 4.3 (examples [21], [48], [49]). The translations given to the majority of examples, including Puskás it-cleft renderings for (61a) and (62a), suggest they are narrow foci. In (63), only the narrow-focus reading appears to be legitimate (examples [63], [64], and [65] are from Komlósy 1986: 218):

Mari [F JÁNOST] látta a kertben.

Mary John-acc 3s-pst-see the garden-ine

'Mary saw JOHN in the garden.' 
Komlósy (1986), however, states that wide foci are indeed possible in some cases. The examples in (64) are given as ambiguous between three possible focus readings. These readings are indicated, as above, by partially superimposed bracketings:

$$
\begin{aligned}
& \text { a. Mari [F [F [F ALMÁT] ]eszik] a kertben.] } \\
& \text { Mary apple-acc 3s-eat the garden-in } \\
& \text { 'Mary eats apples in the garden.' } \\
& \text { b. Mari [F [F [F BETEG] volt] tegnap.] } \\
& \text { Mary sick 3s-be yesterday } \\
& \text { 'Mary was sick yesterday.' }
\end{aligned}
$$

The relevant generalization is that wider foci are possible in sentences where the element that appears in focus position appears there as a "default" (the verb particles, quasi-incorporated complements, and adverbs mentioned above), as in (64). Wider foci are ruled out only when the element appearing in focus position is not in its canonical position, as in (63).

It is also a standard assumption that when the focus position is empty, the focal pitch accent falls on the verb (although prima facie there is no evidence from string order to know whether the verb remains in situ or appears in focus position). In other words, in contrast with its arguments the verb may be realized with focal prominence while remaining in situ (cf. Kiss 1986). Komlósy points out that in such cases focus ambiguity is again present:

$$
\begin{aligned}
& \text { Mari [F [F [F LÁTTA] Jánost] a kertben.] } \\
& \text { Mary 3s-pst-see John-acc the garden-in } \\
& \text { 'Mary saw John in the garden.' }
\end{aligned}
$$

Komlósy's observations presumably point to structural differences between sentences like (63) on the one hand and sentences like (64) and (65) on the other, which we shall ignore here. But Komlósy's sentences also illustrate a characteristic of focus ambiguities in Hungarian. Focus ambiguities result from the fact that, given the right structural context, any of a number of constituents containing the nuclear stress may be interpreted as the focus. The structural phenomenon that allows for this range of foci has often been called "focus projection." In Hungarian nuclear stress falls by default on the immediately preverbal position. Examples (64) and (65) show that in Hungarian focus projects to the right. Elements to the left of the nuclear stress, like Mari, cannot be interpreted as focal. This contrasts with the situation in English shown above by example (21), repeated here as (66):

(66) a. John [F left a note [F on the TABLE]].

b. John $\left[_{F}\right.$ left $[F$ a NOTE $]$ on the table. 
These examples show that English focus (in the VP) projects to the left. In (66b) the locative phrase on the table cannot be interpreted as focal. ${ }^{16}$

Turkish has been described as a language that resembles Hungarian in the way it realizes focus and ground. At first blush, it seems as if the immediately preverbal slot is a focus position and that focal elements are moved to that position. Compare the following two examples from Hoffman (1994: 118). Sentence (67) contains a narrow-focus object (the question Who is Fatma looking for? provides a felicitous contextualization), while (68) contains a narrow-focus subject (in the context, for instance, of the question Who is looking for Ahmet?):

(67) Fatma [F AHMET-i ] ariyor.

Fatma Ahmet-acc seek-3S

'Fatma is looking for Ahmet.'

(68) Ahmet-i [F FATMA] ariyor.

Ahmet-acc Fatma seek-3s

'Fatma is looking for Ahmet.'

In both cases, the focus appears in the preverbal slot regardless of its grammatical function. Nevertheless, there are a number of differences between Hungarian and Turkish. For instance, whereas Hungarian in general does not permit focus in situ (as the ungrammaticality of [60a] suggests), Turkish allows for both intonational and syntactic strategies. In this sense, Turkish shows, in one language, the characteristics of both Catalan and English.

Turkish is an OV language (Erguvanl 1984). Default nuclear stress is on the immediately preverbal slot, as in Hungarian or West Germanic. Take a canonical sentence like (69):

(69) Bir hizmelçi yemek-ten önce masa-nın üzer-i-ne NOT-u a servant meal-abl before table-gen top-poss-dat note-acc birak-tı.

leave-pst-3s

'A servant put the note on the table before lunch.'

No visible operation, prosodic or syntactic, is needed on this string to obtain a reading with narrow focus on the direct object. However, the availability of the two structural strategies becomes evident when an argument other than a direct object is a narrow focus. For each focus assignment there are two options: (a) the focal constituent may appear in the immediately preverbal slot, regardless of its grammatical function, or (b) it may appear in what is arguably its canonical position if it is associated with nuclear stress. ${ }^{17}$ 
(70) When did a servant put a note on the table?

a. Bir hizmełçi masa-nın üzer-i-ne not-u [F YEMEK-ten önce] birak-t1.

b. Bir hizmełçi [F YEMEK-ten önce] masa-nın üzer-i-ne not-u birak-tı.

(71) Where did a servant put a note before lunch?

a. Bir hizmełçi yemek-ten önce not-u [F MASA-nın üzer-i-ne] birak-tı.

b. Bir hizmełçi yemek-ten önce [F MASA-nın üzer-i-ne] not-u birak-t1.

(72) Who put a note on the table before lunch?

a. Yemek-ten önce masa-nın üzer-i-ne not-u ${ }_{F}$ bir HIZMEŁÇI] birak-tı.

b. [F bir HIZMEŁÇI] yemek-ten önce masa-nın üzer-i-ne not-u birak-tı.

It is clear that strategy (b) is akin to the strategy we described when discussing English in section 4.1. But what about strategy (a)? Is it analogous to the strategy followed by Catalan (removing the nonfocal elements from a focus slot) or is it analogous to the strategy followed by Hungarian (moving the focal elements to a focus slot)?

On closer inspection the syntactic strategy followed by Turkish is closer to the type found in Catalan than to the type found in Hungarian. As in Germanic, focus in Turkish projects to the left. The string in (69), repeated here as (73), is multiply ambiguous. The question contextualizations in (a)-(d) highlight the intended focus readings:

(73) Bir hizmełçi [F yemek-ten önce $\left[_{F}\right.$ masa-nın üzer-i-ne $\left[_{F}[F\right.$ NOT-u] birak-t1]]]

a. What did a servant leave on the table before lunch?

b. What did a servant do before lunch having to do with the table?

c. What did a servant do before lunch?

d. What did a servant do?

This contrasts radically with focus projection in Hungarian as discussed above. In Hungarian many preverbal focal constituents do not allow projection to take place and those that do trigger projection to the right, never to the left. This suggests that the syntactic makeup of the two languages is quite different.

If the Turkish syntactic strategy consisted in moving the focus element to the immediately preverbal slot, we would expect projection to be disallowed. As noted, Hungarian permits projection when the canonical 
position of the accent-bearing preverbal element is precisely the preverbal slot and disallows it if the preverbal accent-bearing element appears preverbally as a result of movement. Rather, a more plausible account of the facts is to assume that, in cases like (70a), (71a), and (72b), the ground elements that would otherwise intervene between the focus and the verb are removed from within the focus domain. Note that this is precisely what was shown to happen in Catalan. The syntactic strategies underlying Catalan, (74), and Turkish, (75), would appear to be the same:

El ganivet ${ }_{1}\left[_{F}\right.$ el ${ }_{1}$ vaig ficar $t_{1}$ al CALAIX.] the knife obj 1s-pst-put in.the drawer 'The knife (I) put in the drawer.'

(75) Not- $u_{1}$ [F MASA-nın üzer-i-ne $t_{1}$ birak-tı.] note-acc table-gen top-poss-dat leave-pst-3s 'The note (s/he) left on the table.'

The same would be true for example (68) above. What we would have is not a Hungarian-style movement of the subject into focus position, but rather a Catalan-style movement of the object away from focus position.

In addition, the order of the major constituents outside the focus domain is free, just as in Catalan. If, for instance, the direct object is a narrow focus, the prefocal phrases permit any permutations. This is shown in (76):

(76) What did a servant put on the table?

a. Bir hizmełçi yemek-ten önce masa-nın üzer-i-ne [F NOT-u] birak-t1.

b. Yemel-ten önce bir hizmełçi masa-nın üzer-i-ne [F NOT-u] birak-tı.

c. Masa-nın üzer-i-ne yemel-ten önce bir hizmełçi [F NOT-u] birak-tı.

The nonfocal elements in (76) are tails. Turkish tails may appear in a number of configurations. They may appear prefocally, as shown in this example. They may appear in their canonical position, as in English, when Turkish utilizes the intonational strategy illustrated in (70b), (71b), and (72b). A third option is to place tails in a righthand position, much as Catalan does by means of right-detachment. This alternative is the one discussed in Erguvanl (1984). Erguvanlı argues that phrases representing "backgrounded information" appear in a postverbal position. If Erguvanlı's "backgrounded information" can be equated with our notion of tail, we see that the postverbal strategy is just one of three options 
available in Turkish. ${ }^{18}$ The postverbal strategy is illustrated in (77). Again, the order of the postverbal constituents is free (only some permutations are shown):

(77) What did a servant put on the table?

a. [F NON-u] bırak-tı bir hizmełçi yemek-ten önce masa-nın üzer-i-ne.

b. [F NOT-u] bırak-tı yemek-ten önce masa-nın üzer-i-ne bir hizmełçi.

c. [F NOT-u] bırak-tı masa-nın üzer-i-ne bir hizmełçi yemekten önce.

Turkish links are signalled by both intonation and position. Links, as in Germanic, are associated with a pitch accent but, in contrast to English, must be sentence-initial as well. Kulıçaslan (1994) identifies this accent as a rising tone. The first one of the sequence of ground elements in (76), for instance, will be interpreted as a link if associated with a pitch accent of the appropriate type. Example (78) shows the lefthand restriction on links (from Kilıçaslan 1994: 30-31):

Çaydanlık masa-nın üst-ü-nde ...

teapot table-gen above-poss-dat

'The teapot is on the table ...'
a. ... fakat şekerlig $-i$ dolab-a koy-du-m.
but sugar.bowl-acc cupboard-dat put-pst-3sg
'... but the sugar bowl I put in the cupboard.'
b. *... fakat dolab-a ssekerlig- $i$ koy-du-m.
c. *... fakat dolab-a koy-du-m şekerlig-i.

The direct object must appear initially. It cannot appear postverbally and it cannot appear in its arguably canonical position to the left of the verb.

In Turkish, as in Germanic, an A-accent on the subject of certain sentences gives rise to a focal ambiguity between a narrow-focus reading for the subject and an all-focus, thetic interpretation. This is shown in (79a):
a. [F [F BAŞKAN] öldü. ]
'The PRESIDENT died.'
b. Başkan [F ÖLDÜ.]
c. Başkan [F ÖLDÜ.]
d. [F ÖLDÜ] başkan 
Focus projection may take place in these cases in much the same way in which it takes place in cases in which the preverbal phrase is a complement. Sentences (79b) and (79c)-(79d) illustrate the contrast between all-focus sentences and link-focus and focus-tail sentences. In (79b), baskkan 'the president' is a link. As such, it is associated with a rising tone and must appear in a lefthand slot. In contrast, basskan is a tail in (79c)-(79d). As such, it either appears in a preverbal slot without any intonational marking or it appears postverbally. If we compare the Turkish paradigm with its English equivalent, we see a very close correspondence. The only difference is that (Standard) English does not permit the right-detachment option in (79d). If we compare this paradigm with its Catalan equivalent, we see some points in common as well. Turkish and Catalan share the right-detachment strategy to realize tailhood and the left-detachment strategy to realize linkhood (although Catalan has no link-associated pitch accent). The difference is that Catalan does not permit the option in (79c) for tails. A second difference between Turkish and Catalan is that in the latter all-focus, thetic sentences are associated with the VS order, whereas in Turkish they are associated with the SV order. Whether this is the result of a difference in underlying word order is an interesting issue that we will not address.

\subsection{Morphological strategy}

For the sake of completeness, we will illustrate an additional strategy used in the realization of information packaging in many languages: the use of specific morphemes to mark the focus or (an element of) the ground. The association of a particular morpheme with linkhood ("topic marker") in many languages is well attested. Perhaps one of the most well studied cases is Japanese wa. Kuno (1972) describes two uses of wa that correspond to our notion of link, one of them being equivalent to what we called contrastive links. $W a$ in (80) identifies the subject noun phrase as a link (from Kuno 1972: 290):

(80) John-wa sono hon-o yonda.

John the book read

'John read the book.'

The English analogue of (80) would have a B-accented subject (although, as noted, the B-accent on noncontrastive subject links may be omitted), while the Catalan analogue would have a left-detached subject. As with English B-accented links, wa-marked phrases need not appear sentenceinitially, although lefthand placement is the default option. 
Focushood is associated with particular morphological realizations in a number of languages as well. Schauber (1978), for instance, describes the use of focus morphemes in Navajo. The following example (Schauber 1978: 148) illustrates narrow focus on the object, (81a), and narrow focus on the subject, $(81 \mathrm{~b})$ :

(81) Jáan chidíish yiyiílch@.

John car.Q 3s-past-wreck

'Did John wreck the CAR?'
a. Nda, (Jáan) [F chidítsoh ga'] (yiyíítch@). no John truck F 3s-past-wreck 'No, John wrecked the TRUCK.'
b. \#Nda, [F Bíl ga'] (chidí yiyiílch@).
no Bill $F$ car 3s-past-wreck
'No, BILL wrecked the car.'

Navajo is an SVO language and SVO is the order for both (81a) and (81b). The informational difference between the two sentences is realized by means of the placement of the focus morpheme $g a^{\prime}$. In (81) only (a), with focus on the object, is a felicitous answer to the question whether what John wrecked was the car. Sentence (b) is an answer to the question Was it John that wrecked the car? In English (b) would be a felicitous answer, since the answerer can ignore the actual question and act as if $\mathrm{s} /$ he was updating a different input context, but Navajo does not permit such an option.

Many languages that use the morphological strategy, including Navajo, have more than one focus morpheme. Often different morphemes are used for foci in declarative or interrogative sentences or for different types of focus. An interesting case is Vute (Thwing and Watters 1987). Vute appears to have two focus morphemes (in the perfective aspect): $t i$ is used in sentences in which the focus is the verb or a verbal projection and in cases of verum focus (e.g. polarity, tense, aspect), and $a$ is used in sentences in which the (narrow) focus is a nonverbal category. The use of the two morphemes is in illustrated in (82), from Thwing and Watters (1987: 103):
a. Mvèn yi $\beta$ wáb-na tí ngé cene. chief past perf-buy-iobj perf-F him chicken 'The chief bought him a chicken.'
b. Mvè̀n yi $\beta$ wáb-na-á $\eta$ gé cene Pá. chief past perf-buy-iobj-perf him chicken $F$ 'The chief bought him a chicken.'


Interestingly, however, the $\dot{a}$ form is used for verbal categories too. Roughly, it appears that $t i$ is used with foci that appear in tailless instructions and $a$ with foci that appear in instructions that contain a tail (when the focus alters a condition that is already present on a file card in the input information state).

\subsection{A crosslinguistic comparison}

In this section, the structural realization of several ground-focus partitions in English, Catalan, Dutch, and Turkish is contrasted. The English examples, originally Jackendoff's, are adapted from Steedman (1991). The question contextualization is meant to set up both the choice of link (triggered by the first 'what-about' question) and the choice of focus (the answer to the second question). As above, italics represent a link-associated accent (a $\mathrm{L}+\mathrm{H}^{*}$ pitch accent in English). The bracketing delimits the focus, which in Catalan coincides with the core clause. The items not marked either way are tails:

What about the boys? What did they do?

a. Eng.: Fred ${ }_{\mathrm{F}}$ ate the BEANS.]

b. Cat.: El Pere ${ }_{1}\left[\mathrm{~F}\right.$ es va menjar els FESOLS $t_{1}$.]

c. Dutch: Fred heeft [F de BONEN opgegeten.]

d. Dutch: Fred ${ }_{1}$ die $_{1}$ heeft [F de BONEN opgegeten.]

e. Turk.: Oya [F FASULYE-ler-i ye-di.]

What about the boys? What did they eat?

a. Eng.: Fred ate [F the BEANS.]

b. Cat.: El Pere ${ }_{1}\left[\mathrm{~F} \mathrm{t}_{\mathrm{v}}\right.$ els FESOLS $\mathrm{t}_{1}$, ] es va menjar ${ }_{\mathrm{v}}$.

c. Dutch: Fred heeft $[\mathrm{F}$ de BONEN] opgegeten.

d. Dutch: Fred die $_{1}$ heeft $[\mathrm{F}$ de BONEN] opgegeten.

e. Turk.: Oya [F FASULYE-ler-i] ye-di.

What about the boys? What did they do to the beans?

a. Eng.: Fred ${ }_{\mathrm{F}}$ ATE] the beans.

b. Cat.: El Pere ${ }_{1}\left[\mathrm{~F}\right.$ se'ls $_{2}$ va MENJAR $t_{2} t_{1}$, els fesols ${ }_{2}$.

c. Dutch: Fred heeft de bonen [F OPgegeten.]

d. Dutch: Fred $_{1}$ die $_{1}$ heeft de bonen [F OPgegeten.]

e. Turk.: Oya [F YE-di] fasulye-ler-i.

What about the veggie dishes? What happened to them?

a. Eng.: [F FRED ate] the beans.

b. Eng.: The beans $s_{1}\left[\right.$ FRED ate $\mathrm{t}_{1}$ ] 
c. Cat.: Els fesols ${ }_{1}\left[{ }_{F}\right.$ se'ls $_{1}$ va menjar el PERE.]

d. Dutch: De bonen heeft [F FRED opgegeten.]

e. Dutch: De bonen ${ }_{1}$ die $_{1}$ heeft [F FRED opgegeten.]

f. Turk.: Fasulye-ler-i [F OYA ye-di.]

What about the veggie dishes? What did Fred do to them?

a. Eng.: Fred ${ }_{\mathrm{F}}$ ATE] the beans.

b. Eng.: The beans ${ }_{1}$ Fred [ ATE t $_{1}$.]

c. Cat.: Els fesols ${ }_{1}\left[\right.$ se'ls $_{1}$ va MENJAR $\left.t_{1} t_{2}\right]$, el Pere ${ }_{2}$.

d. Dutch: Fred heeft de bonen [F OPgegeten.]

e. Dutch: De bonen heeft Fred [F OPgegeten.]

f. Dutch: De bonen ${ }_{1}$ die $_{1}$ heeft Fred [F OPgegeten.]

g. Turk.: Fasulye-ler-i Oya [F YE-di.]

h. Turk.: Fasulye-ler-i [F YE-di] Oya.

a. Eng.: [F FRED] ate the beans.

b. Eng.: The beans [F FRED] ate.

c. Cat.: Els fesols ${ }_{1}\left[\mathrm{t}_{\mathrm{v}} \mathrm{t}_{1}\right.$ el PERE, ] se'ls va menjar ${ }_{\mathrm{v}}$.

d. Dutch: [F FRED] heeft de bonen opgegeten.

e. Dutch: De bonen heeft [F FRED] opgegeten.

f. Dutch: De bonen ${ }_{1}$ die $_{1}$ heeft [F FRED] opgegeten.

g. Turk.: Fasulye-ler-i [F OYA] ye-di.

We note that in English and Dutch there is a choice in the realization of links. In both languages links can be realized in situ provided they are realized with the link-associated intonation. In Dutch, fronting of links appears to be the preferred option, and in spoken Dutch, the use of the contrastive dislocation pattern for links (cf. [83d], [86e]) is prevalent.

In Catalan, links always appear in a left-detached position, and this seems to hold for Turkish as well. The parallelism between English and Dutch is apparently only interrupted in (86), where the Dutch in-situ version (according to the speakers consulted) is not available. The intended informational reading for (86) is one where the focus consists of both the verb and the subject. Interestingly, if the link were to appear in situ in (86) the two elements in the focus would be discontinuous, as shown in (89b):

En de bonen? Wat is er daarmee gebeurd?

a. De bonen heeft [F FRED opgegeten.]

b. \#Fred heeft de bonen opgegeten.

Whether this is the reason for the unavailability of in-situ placement for the link in the context of (86) will be left as an open question. 
Foci in all the languages surveyed are marked by sentential nuclear stress. In English and Catalan nuclear stress tends to fall on the rightmost constituent of the focal segment. In Dutch and Turkish the same applies, except when, within a wide focus, the rightmost constituent is the verb. In this event nuclear stress falls on the element that is left-adjacent to the verb. The means by which the association between nuclear stress and the focus segment is attained varies from language to language. Germanic allows several different intonational contours on one unique string. Catalan, in contrast, displays a constant intonational structure: nuclear stress is necessarily associated with the righthand boundary of the core clause. In order to have foci associate with the nuclear stress, nonfocal elements must be removed from the core clause. Turkish allows for both options: both intonational contour and string order can be manipulated with extreme freedom.

English and Dutch tails remain in situ and deserve no special structural identification, other than being destressed. In Catalan tails cannot remain in their canonical position and must be right-detached. Turkish tails present a number of options: they may remain in situ, they may appear to the left of the preverbal focus domain (but to the right of links), or they may be right-detached to the postverbal field.

Let us complete the crosslinguistic comparison with (90) and (91), where linkhood falls on the verb. While English may express this intonationally, Catalan, as expected, may not. The expected Catalan analogue of an English B-accent is a left-detachment, and indeed this is what we find in the case of verbal links too: an infinitival copy of the verb is leftdetached, in a fashion analogous to the German (56b) above. Inflection remains with the verbal copy left behind within the clause. Dutch may also opt for a left-detachment strategy ([91c]) with the appropriate verbal forms, but on other occasions prefers an exclusively prosodic solution $([90 \mathrm{c}]):{ }^{19}$

a. Eng.: Fred ate [F the BEANS.]

b. Cat.: De menjar ${ }_{v}\left[F\right.$ es va menjar ${ }_{v}$ els FESOLS $t_{1}$, ] el Pere ${ }_{1}$.

c. Dutch: Fred at [F de BONEN.]

I know who cooked the beans. But then, who ate them?

a. Eng.: [F FRED] ate the beans.

b. Cat.: De menjar ${ }_{v}\left[{ }_{F}\right.$ se'ls $_{1}$ va menjar ${ }_{v} t_{1}$ el PERE, $]$ els fesols ${ }_{1}$.

c. Dutch: Gegeten heeft $\left[{ }_{F}\right.$ FRED] de bonen. 
The following table summarizes the data discussed in this section. It focuses on the intonational and syntactic operations available in each one of the four languages discussed:

(92)

\begin{tabular}{lllll} 
& English & Catalan & Dutch & Turkish \\
\hline INTONATION & plastic & nonplastic & plastic & plastic \\
& A \& B accents & A accent & A \& B accents & A \& B accents \\
\multirow{2}{*}{ WORD ORDER } & links & ground in & links & ground or foci in \\
& optionally front & detachment slots & normally front & designated slots?
\end{tabular}

Catalan intonation is "nonplastic" in that it does not allow variable placement of nuclear stress qua marker of focushood. Germanic and Turkish, in contrast, possess a "plastic" intonation. In addition, Germanic and Turkish use a richer repertoire of accents than Catalan: where the former languages exploit both A and B accents, Catalan uses only one type. In Germanic, where an intonational strategy is available for the marking of linkhood, syntactic operations on links are only optional and must always cooccur with the intonational marking. Catalan opts for the obligatory syntactic marking of groundhood. Turkish instantiates both the Catalan and the English strategies: intonational marking is available, but a complete set of syntactic operations is also used to realize information packaging. We remain agnostic on whether these operations affect ground elements or focal elements, although the evidence reviewed above suggests the correct hypothesis is the former. We leave this for Turkish syntacticians to ascertain.

A crosslinguistically motivated proposal for how information packaging and its varied structural manifestations may be integrated into grammar is found in Vallduví and Engdahl (1995). This paper proposes an HPSG analysis of the interaction of information packaging and the structural dimensions of language. The multidimensional constraintbased architecture of HPSG lends itself very well to expressing the mutual constraints on interpretation, syntax, phonology, and morphology that so diversely characterize focus-ground in different languages. The analysis focuses on English and Catalan, but extensions to other languages are being undertaken.

\section{Other pragmatic issues}

This section reviews a number of interpretive and structural issues that are of relevance for information packaging. First, we will focus on the relation between information packaging and cognitive status. Both phenomena pertain to the attentional structure of discourse and indeed are 
not always teased apart in the literature. Then, we offer some remarks on the relationship between focus-ground and presupposition using Delin's observations about the semantics and pragmatics of $i t$ clefts as a probe (Delin 1989, 1992). Finally, we discuss some issues concerning the relationship of focus and intonation, and we emphasize the need to distinguish informationally motivated effects on intonational structure from effects triggered by other discourse phenomena.

\subsection{Cognitive status}

Cognitive status refers to a property of discourse referents (see Gundel et al. 1993). Discourse referents are either familiar ("given" or "known") or novel ("new" or "unknown") to the hearer. Speaker assumptions about whether their interlocutors are familiar with a particular discourse referent arguably determine the realization of this referent in a given sentence. Within the file metaphor utilized in section 3 to describe information states, familiar referents are those for which a file card already exists at the time of utterance, while novel referents are those for which there is no preexistent file card (we are abstracting away from a number of categorization issues for the sake of exposition). It is generally agreed that determiners, in languages that possess them, play an important role in the realization of cognitive status. Roughly, identified noun phrases express novel discourse referents and indicate that a new file card has to be created, whereas familiar referents are realized through definite noun phrases. Familiar referents can be more or less "accessible" (Ariel 1988): there are "dormant" file cards and "activated" file cards. The former are realized as full noun phrases to indicate that the dormant file card must become activated. The latter, which are also said to be "salient" or "in focus" (see section 2.1.1), may be realized as pronouns.

We noted in section 3 that cognitive status and information packaging must be seen as operating simultaneously, yet independently, within the attentional structure of discourse. Cognitive status provides hearers with instructions for file-card management and information packaging provides them with instructions to update the file cards. The independence of the two dimensions can be seen clearly in examples like (93). Phrases denoting salient, familiar referents - pronouns - can be either focal, as in (93a), or ground, as in (93b) (see also example [4] in section 2.1.1):
a. I like [F HIM.]
b. Him [F I LIKE.] 
There are, of course, a number of correlations between the two dimensions. Novel referents, for instance, are generally introduced in the discourse by appearing in the focal segment of a sentence rather than as part of the ground, and links must denote familiar referents of one kind or another. As noted, cognitive status is signalled through the choice of lexical realization of the noun phrase. In contrast, information packaging, as shown in the previous sections, is structurally realized through syntactic operations, intonational phrasing, and/or morphological marking. This division of labor is assumed in, for instance, Reinhart (1982), Prince (1986), Gundel (1988), Gundel et al. (1993), and Vallduví (1992). This constitutes a neat correlation between form and discourse interpretation.

This picture, however, is not unanimously agreed upon. In Givón $(1983,1992)$, for instance, both definiteness and word-order permutations are structural reflections of cognitive status or, as it is called in this framework, "topicality." Discourse referents are hierarchically ranked according to topicality. Their ranking determines their structural realization along the following lines, starting with the highest degree of topicality and descending along the scale:

Topicality hierarchy:

Zero anaphora $>$ weak pronouns $>$ strong pronouns $>$ right-detachment $>$ neutral order $(+$ definite $)>$ left-detachment $>$ Y-movement $>$ clefts $>$ indefinite NPs.

This correlation between form and function is supported by studies on several languages carried out in this paradigm. It is interesting to note, however, that definiteness clusters at the periphery of the hierarchy. There is no reason to expect such a distribution if topicality is the sole underlying function driving structural realization. In addition, there are a number of empirical problems with this view. In Catalan and other languages, nonspecific indefinites can be right-detached. In light of the topicality hierarchy, this is totally unexpected, since indefinite noun phrases are lowest in topicality and right-detached noun phrases are among the highest (see Vallduví 1994b for a discussion of detachment and topicality). Nevertheless, there is one particular language type in which word order has been argued to especially come into play in the realization of cognitive status: languages that lack overt determiners, like Finnish. Given the lack of an NP-level strategy to realize cognitive status, one would think that these languages would utilize other structural means to express familiarity and novelty. It is possible, however, that intonational means are used instead or that cognitive status remains unexpressed and is inferred from independent discourse processes (see Välimaa-Blum 1988 for a discussion of the factors affecting word order in Finnish). 
5.1.1. Topic fronting in Swedish. The topicality paradigm is well equipped to account for the function of configurations like "topic fronting," which exist in a number of languages including Swedish (Andersson 1974). Topic fronting is characterized by the sentence-initial placement of a weak pronominal, and its function appears to be to signal topicality in the sense that the expression denoting the most topical or salient referent in the sentence is fronted. This construction is illustrated by the examples in (95). Both (95a) and (95b) are licit continuations to (94):

(94) I går fick jag en bok

yesterday 1s-pst-get I a book

'Yesterday I got a book ...'

a. Den ska jag läsa i kväll

it fut I read tonight

b. Jag ska läsa den i kväll

I fut read it tonight

'I will read it tonight.'

The weak pronouns den 'it' and jag ' $I$ ' in (95a) and (95b), respectively, are unstressed. They denote topical or salient discourse referents. Note that topic fronting is not analogous in any interpretive sense to the linkfronting configurations (e.g. left-detachment, topicalization) discussed in section 4 (even though in Swedish both topic fronting and link fronting are V2 structures). The lefthand phrase in the link-fronting configurations is either a full phrase or a strong pronoun, but never a weak pronoun. In English, in addition, it bears its own pitch accent. As noted, the role of link phrases is to establish a particular locus of update in the input information state. Links are used when the locus of update of a sentence $S_{n}$ differs from the locus of update of $S_{n-1}$. As a consequence, even though links must denote familiar referents, linkhood and a high degree of salience rarely coincide. Topic fronting, in contrast, fronts an element to signal its status as, in a sense, a continuing topic inherited from the previous clause. This discourse function is difficult to express in the threeway distinction of Vallduvi (1992). It is illustrated in the sequence in (96) from the tale Barnens dag $i$ Bullerbyn by Astrid Lindgren:

(96) a. Sen gick vi till stora grissuggan.

then went we to the big sow

'Then we went to the big sow.'

b. Hon hade just fått smågrisar, nio stycken.

she had just had piglets nine ones

'She had just had piglets, nine of them.' 
c. Dom tyckte Kerstin om att titta på.

them liked Kerstin to watch

'Kerstin liked to watch them.'

Topic fronting also seems to play a role in establishing a temporal sequencing between events in a narrative. The fronted pronouns carry the narrative forward in a way that is similar to uses of and then ... and so ... in English. In fact, topic fronting is very common with temporal adverbs like då and sen 'then'. Topic fronting is unknown in languages like Catalan and English (this is expected in the former, since weak pronouns are either zero or syntactically dependent clitics) but does have an analogue in other Germanic languages. In Dutch an analogous construction exists, although the class of elements that undergo topic fronting is further constrained (mostly, it is restricted to demonstratives).

5.1.2. Word order and strong/weak readings. The word-order dimension appears to correlate with additional aspects of definiteness and nounphrase interpretation. A case in point is the so-called distinction between the strong (or partitive) and weak readings of certain indefinite and quantified expressions. Strong readings have also been called presuppositional (Diesing 1992), specific (Enç 1991), and, to some extent, d-linked (Pesetsky 1987). The contrast between strong and weak is discussed in de Hoop (1992) and illustrated by her examples in (97):

(97) a. Er zijn gisteren twee krakers opgepakt.

there are yesterday two squatters arrest-pple

'Two (of the) squatters were arrested yesterday.'

b. Er zijn twee krakers gisteren opgepakt.

'Two *(of the) squatters were arrested yesterday.'

In (97a) the quantified noun phrase appears postadverbially and may have a strong and a weak reading, but in (97b), where it appears preadverbially, it must have a strong reading. In the strong/partitive reading two squatters is interpreted as denoting two squatters out of a larger salient set of squatters. In this reading, two squatters may be paraphrased by two of the squatters. The weak reading of two squatters simply denotes a set of squatters with a cardinality of two.

Why is the strong/partitive reading obligatory in the preadverbial noun phrase in (97b)? Why is the interpretation not free as in the postadverbial case? Interestingly, a similar phenomenon is found in Catalan. Quantified noun phrases within the core clause may have both a strong/partitive reading and a weak reading. In contrast, if they appear in a left-detached slot they must have a strong/partitive reading. As noted above, the left- 
detached position in Catalan is associated with a link interpretation. Vallduví (1993b) suggests that only the strong/partitive reading of these noun phrases is compatible with a link interpretation. Whether there is a parallel explanation for the Catalan and the Dutch data remains to be seen. If there is, one would have to conclude that the preadverbial slot in the Dutch sentence is necessarily associated with a link interpretation as well.

\subsection{Clefts}

Clefting, especially it clefts, has been traditionally considered one structural strategy to reflect informational partitions (Chomsky 1971; Prince 1978; Akmajian 1979 [1970]). For example, it has been argued that an it cleft like (98a) is informationally equivalent to the subject-focus sentence in $(98 \mathrm{~b})$ :

(98) a. It is John who left.

b. [F JOHN] left.

It is true that (98a) and (98b) may be informationally synonymous, but it is also true that they need not be. In some contexts the clefted constituent is in the ground rather than the focus. Sentence (99a) is informationally synonymous with (99b), not with (99c) (Delin 1989):
a. Why are you so fond of Harry?
It is Harry that taught me how to TANGO.
b. Harry [ taught me how to TANGO].
c. \#[F HARRY] taught me how to tango.

This evidence suggests that the basic role of $i t$ clefts in discourse is not to realize focus-ground partitions. Delin (1992), for instance, argues that it clefts are markers of classic presupposition. The nonclefted part of an it cleft always encodes a presupposition and the clefted phrase the corresponding assertion. The presupposition, however, maybe be focus or ground depending on the different contextual conditions affecting it.

There are several approaches to presupposition in the literature, and Delin (1992) favors the anaphoric theory of presupposition of van der Sandt (1988). What is important to bear in mind here is that presupposition and ground represent two different kinds of constraints on contexts (see also Steedman 1991: 276). Focus-ground and presupposition-assertion are independent of each other. The following table compares the two partitions in four different sentence types (adapted from Figure 2 in 
Delin 1995). All examples should be taken in their narrow-focus reading (John in [a] and [c] and left in [b] and [d]):

Utterance Ground Focus Presupposition Assertion

\begin{tabular}{llllll}
\hline a. & JOHN left & left $(x)$ & $x=j$ & - & left $(j)$ \\
b. & John LEFT & $P(j)$ & $P=$ leave & - & left $(j)$ \\
c. & It was JOHN who left & left $(x)$ & $x=j$ & left $(x)$ & $x=j$ \\
d. & It was John who LEFT & $P(j)$ & $P=$ leave & left $(x)$ & $x=j$
\end{tabular}

Focus-ground and presupposition-assertion overlap in only one out of four possible cases. It is precisely the case in which the clefted phrase in an it cleft is both the assertion and focus.

The distinction between ground and presupposition is an important one and the issue is especially confounded by the fact that the term "presupposition" has often been used to denote the ground. Lakoff (1971) already disputed the use of the word "presupposition" to denote the ground, and it was partly disagreement on the use of the term "presupposition" that led Erteschik-Shir (1986) to reject the notion of focus in favor of "dominance." Delin's data offer evidence that assertionpresupposition and focus-ground are orthogonal to each other and that their functions in the dynamics of communication must be distinct (see Vallduví 1994a for further discussion).

\subsection{Other intonational effects}

The relationship between intonation and information packaging in English-type languages is a complex one. English is a plastic language that utilizes its malleable intonation to realize different focus-ground partitions: nuclear stress is shifted to different clausal positions in order to fall on the right focus constituent. The fact that nuclear stress is associated with a focal phrase regardless of the position of this phrase in the clause has led to a number of undesirable overgeneralizations. For example, sometimes one encounters claims that ALL pitch accents in a sentence have the same informational import. As Steedman (1991: 276) notes, the problem is compounded by the fact that the term "focus" is also used, particularly by phonologists, to designate any pitch accent within a phrase. As shown throughout this paper, however, it is important to note that some pitch accents are associated with the ground rather than the focus. In English, for instance, (nonsubject and contrastive subject) links must be realized with a B-accent. 
There are, however, other uses of pitch accent that are often analyzed as signalling informational focushood but appear to owe their existence to independent factors. The next two sections briefly discuss two of these uses: metalinguistic corrections and string-based deaccenting. A more comprehensive look into the relationship between informational focus and pitch accent (and quantificational nuclei) is found in Vallduví and Zacharski (1994).

5.3.1. Metalinguistic corrections. In section 4 Catalan was described as nonplastic because it does not allow variable placement of nuclear stress qua marker of focushood. However, it is not the case that nuclear stress is never allowed to depart from its core-clause-final collocation. Take an example like (101):

(101) Posarem "EXTENSIÓ" en aquesta oració (no
1p-fut-put extension in this sentence not
"INTENSIÓ").
intension
'We'll use "EXtension" in this sentence (not 'INtension').'

Sentences like (101), however, are used only as metalinguistic correction. Sentence (101) must correct or repair some aspect of an earlier utterance related to the accented item. There is no "genuine" linguistic use for this sentence. Its use to signal focus-ground partition is illicit:

(102) Which term will we use in this sentence? \#Posarem "EXTENSIÓ" en aquesta oració.

In English, however, there is no apparent difference in the intonational characteristics of metalinguistic corrections and narrow foci. The correction in (103a) and the narrow focus in (103b) do not differ structurally in any obvious way:

(103) a. We'll use "EXtension" in this sentence (not "INtension").

b. Which term will we use in this sentence?

We'll use [F "EXTENSION"] in this sentence.

This structural identity has lead to unified accounts of the two phenomena in English. Giving a unified treatment to (103a) and (103b), however, would not capture the fact that in Catalan these two sentence types are realized through different structural means. The Catalan equivalent of (103b) must be realized with the syntactic means appropriate for the focus-ground partition it encodes: 
(104) Which term will we use in this sentence?

a. [F "EXTENSIÓ",] posarem en aquesta oració.

b. [F $\left(\mathrm{Hi}_{1}\right.$ posarem) "EXTENSIÓ",] en aquesta oració ${ }_{1}$. 'We'll use "EXTENSION" in this sentence.'

The two options in (104) are possible. Both involve the syntactic marking associated with focus-ground partitions, that is, dislocation of the nonfocal elements (although in [104b] the verb remains vacuously within the focal domain as a weak proform). Both options are crucially different from the corrective form in (101).

The contrast between the metalinguistic correction in (103a) and (103b) is clear. Unfortunately, in many cases the distinction between a genuine informational use and a metalinguistic use is harder to establish without substantial dependence on general context information. English strings like (105) are completely ambiguous between the two readings. On one reading (105) is analogous to (103a) and on the other it is analogous to $(103 \mathrm{~b})$ :

\section{(105) I introduced my EX to Sue.}

In Catalan, as expected, there are two structural options available in lieu of the sole string (105). The metalinguistic use in (106) is realized by an intonational shift, whereas the genuine focus-ground partition in (107) must involve a syntactic strategy:

(106) a. Vaig presentar el meu EX a la Sió, (no el 1s-pst-introduce the my ex to the Sió, not the MALCOLM X).

Malcolm $\mathrm{X}$

'I introduced my EX to Sió (not MALCOLM X).'

(107) a. [F El meu EX], vaig presentar a la Sió.

b. $\left[\mathrm{F}_{\mathrm{F}}\left(\mathrm{Li}_{1}\right.\right.$ vaig presentar) el meu EX], a la Sió ${ }_{1}$.

'I introduced [F my EX] to Sió.'

An analogous situation seems to hold in Hungarian (cf. Horvath 1986: 92). The only case in which a non-syntactically marked focus can receive nuclear stress is when this accented element is understood as a metalinguistic correction. Note that all narrow-focus sentences, that is, groundfocus sentences with a tail, may also have somewhat of a correction flavor to them as a consequence of their informational interpretation. However, while a metalinguistic correction is a correction of a (hearer's) UTTERANCE, an instruction with a tail "corrects," if anything, some aspect of the hearer's INFORMATION STATE. 
5.3.2. Deaccenting. Consider English sentence (103a) in the previous section and compare it to its Catalan analogue (101). Nuclear stress in (103a) does not fall on the lexically stressed syllable within the accented item (-ten-) but rather on the syllable that is the subject of correction (ex-). In Catalan, in contrast, nuclear stress goes with the lexically stressed syllable (-sió) even if the corrected bit is another syllable (ex-).

This contrast illustrates another intonational phenomenon that affects the placement of pitch accents in English but shows no structural effects in Catalan: string-based deaccenting. Deaccenting shifts the default placement of A-accents and B-accents within the focus and link segments, respectively. In (108) the pitch accent on the old men would normally appear on men. The previous mention of the men, however, causes the deaccenting of men in the second mention and the A-accent is shifted to the left on to old. This example is adapted from van Deemter (1994: 19):

(108) The men in the hospital looked horrible. Especially the OLD men.

Deaccenting is not attested in Catalan in cases like (108) either. In Catalan, if a phrase is associated with a pitch accent, that pitch accent is realized on the rightmost stressable item in that phrase, regardless of its being previously mentioned in the discourse or not. Compare English (108) with Catalan (109): ${ }^{20}$

(109) Els vells de l'hospital feien pena. Sobretot els the old of the.hospital 3p-impf-make pity especially the homes VELLS.

men old

'The old people at the hospital looked horrible. Especially the old men.'

The focus phrase the old men in (108) or els homes vells in (109) is realized with a focal pitch accent both in Catalan and in English, as required by the realization of information packaging in each language. In addition, the English phrase has undergone a deaccenting process, thus shifting the accent from men to old. The Catalan phrase has no deaccenting, because no such process is available in Catalan. The pitch accent falls on vells, even if vells is mentioned in the previous sentence.

Van Deemter (1994) phrases the licensing conditions for deaccenting in terms of "anaphoricity." His notion of anaphoricity applies to discourse referents and in that respect is analogous to familiarity/novelty (cognitive status). In his paradigm, an expression introducing a novel referent is always assigned a pitch accent. However, this expression may contain a subexpression that denotes a familiar entity, in which case the subexpression is deaccented. Van Deemter also points out that sometimes 
a more general notion of anaphoricity is needed (concept-givenness) to account for some cases of deaccenting. Van Deemter's approach, however, predicts that pronouns will always be deaccented and requires an independent mechanism to account for the occurrence of strong pronouns like those in (93) in section 5.1. In addition, the unequivocably stringbased deaccenting observed in (103a) will have to be analyzed, in van Deemter's framework, as an independent effect. The role that information packaging plays in determining intonational structure in English is completely ignored as a separate dimension. Teasing apart the intonational effects of information packaging from the intonational effects of an independent process of deaccenting should provide a more accurate picture of the English facts. In addition, it captures the fact that in Catalantype languages informationally based intonational operations and stringbased deaccenting effects have completely separate manifestations. Otherwise, the following striking crosslinguistic difference between Catalan and English remains unaccounted for:
a. This [F I'll discuss in the first SECTION.]

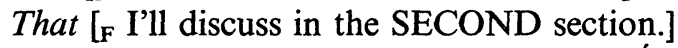
b. Això ${ }_{1}\left[\mathrm{ho}_{1}\right.$ tractaré a la primera SECCIÓ.] Això $_{2}\left[\mathrm{~F}_{2} \mathrm{ho}_{2}\right.$ tractaré a la segona SECCIÓ.]

In the second conjunct in English (110a), section, which should bear the focal A-accent, is deaccented (optionally, it may also be possible to deaccent section in the first conjunct). No such deaccenting takes place in the Catalan analogue in (110b).

As noted, deaccenting also affects B-accents and, therefore, links in English. The following is an adaptation of an example in Steedman (1991):
(111) $\mathrm{S}_{1}$ : Oh, I didn't know both of them have a doctorate ...
$\mathrm{S}_{2}$ : Yes, but
Mary's doctorate [F is in CHEMISTRY]
$\mathrm{L}+\mathrm{H}^{*} \quad \mathrm{LH} \% \quad \mathrm{H}^{*} \quad \mathrm{LL} \%$
and Anna's doctorate is in LAW.

In Steedman (1991) a variant of (111) is used to illustrate the distribution of accents within ground and focus. Steedman suggests that within both the ground and the focus (his theme and rheme) a further distinction is needed between elements that are accented and elements that are unaccented. He calls the former "emphasis" and the latter "deemphasis." Within the link in (111), Mary's is the emphasis and doctorate the deemphasis. This proposal is very much along the lines of what an analysis in terms of string-based deaccenting would predict. The B-accent 
would normally fall on doctorate. However, doctorate is subject to deaccenting and, therefore, the pitch accent falls on Mary. In this case, there is no comparable visible effect in Catalan, since Catalan links are not associated with any particular accentual realization.

Krifka 1991-1992 takes the phrasal deaccenting phenomenon as proof that the notions of ground and focus are recursive, that is, that within the ground there is a further ground-focus split. About (111), for instance, it would be claimed that Mary's is a focus within the ground because it is associated with a pitch accent. On close inspection, however, there is no need to argue for such a position. We know that links are associated with a pitch accent, and we have seen here that an independent process of deaccenting may alter the default placement of pitch accents within both links and foci. The null hypothesis, then, is that the pitch accent on Mary has nothing to do with focushood.

\section{Conclusion}

The instruction-based approach to information packaging provides a language-independent means to describe notions like focus and ground. The comprehensive but limited set of informational primitives and their combinations afforded by this approach has proven advantageous in establishing correspondences across languages. This paradigm has allowed us to identify informationally equivalent sentences in a variety of languages and bring out important differences in the way different languages realize information packaging. Observations about the different manifestations of information packaging can thus be made in a systematic way. For instance, we have noted that linkhood is realized through the assignment of a B-accent in English (regardless of syntactic position) and through placement in a lefthand syntactic slot in Catalan (no intonational marking). The equivalence of in-situ B-accenting in English with leftdetachment in Catalan had not been pointed out before, and, in particular, there is no mention in the literature of the equivalence of verb leftdetachment and B-accented verbs. We have also noted that tailhood in Turkish appears to surface in a number of ways: leftward movement, rightward movement, and in-situ deaccenting. Turkish links, in contrast, may use only the first of these strategies. And we have pointed out that, in thetic sentences, Catalan VS order is analogous to the assignment of an A-accent to the subject in English.

These examples should suffice to illustrate the advantages of using a systematic description of informational meaning like the instructionbased approach in the contrastive study of languages. This article also 
contains pointers to areas in which crosslinguistic analysis may prove useful. English and German, for instance, differ in how they treat linkrelated accents. In English this accent must be a complex B-accent, whereas in German links and foci may be accented in the same way $\left(\mathrm{H}^{*}\right)$. The question arises of what prosodic cues, if any, are used to distinguish linkhood from focushood in German and, indeed, of what the range of intonational elements is that can be used for the realization of the different informational primitives. We also discussed the contrasting focus-projecting patterns in Hungarian and Turkish. If we can establish what the exact correspondences are between the two languages, we can then explore what the syntactic facts are - presumably having to do with branching structure - that determine the differences in focus projection with a firm grip on the interpretive facts. With a clear picture of what information packaging is we can also approach languages without determiners (Finnish) and look at the contribution of word-order variation to the marking of cognitive status without fear of wrongly analyzing realization of referential novelty for realization of focushood or realization of familiarity for realization of groundhood.

Some of the issues reviewed in section 5 point in yet another direction. Contrastive analysis of the realization of information packaging may prove revealing in establishing the correct categorization of different phenomena that are sometimes lumped together under the same label because they happen to exploit the same structural dimension within a given language. This is clearly the case with "focus" in Germanic. The term "focus" has been used to designate any intonationally prominent element in a sentence and, often, a unified semantics has been given for "focus." Crosslinguistic considerations, however, suggest that placement of nuclear stress on a particular item may possibly be the structural reflection of different pragmatic or semantic phenomena. The accentual shifts triggered by string-based deaccenting in English, which have no correspondence in Catalan-type languages, are an example of this.

The crosslinguistic insights that information packaging as a welldefined linguistic dimension provides are extremely valuable. On the one hand, of course, they are central for the study of discourse typology, translation, and contrastive linguistics in general. On the other, they constitute an excellent probe into all dimensions of language. They shed light on language-internal issues concerning syntax and intonation, and they will help identify distinct pragmatic and semantic phenomena and the way in which they interact.

Received 27 June 1995

University of Edinburgh

Revised version received

8 January 1996 


\section{Appendix A. Selected references grouped by articulation}

- theme-rheme (Ammann 1969 [1928]; Daneš 1968 [1957]; Firbas 1964, 1971, 1975; Halliday 1967, 1985; Contreras 1976; Steedman 1991).

- topic-comment (Mathesius 1915; Hockett 1958; Strawson 1964; Gundel 1974, 1988; Dahl 1974; Li and Thompson 1976; Bland 1980; Reinhart 1982; Davison 1984).

- topic-focus (Sgall and Hajičová 1977, 1978, and many others by them and their associates [cf. Hajičová 1984 for a list]; von Stechow 1981).

- focus-presupposition or focus/open-proposition (Akmajian 1979 [1970]; Chomsky 1971; Jackendoff 1972; Dahl 1974; Rochemont 1978, 1986; Wilson and Sperber 1979; Williams 1981; Prince 1981, 1984, 1986; Culicover and Rochemont 1983; Selkirk 1984; Ward 1988; Lambrecht 1987, 1988).

- oldinfo-newinfo (Välimaa-Blum 1988).

- dominance (Erteschik-Shir 1973, 1979, 1986; Erteschik-Shir and Lappin 1979, 1983).

- given-new (Halliday 1967, 1985; Clark and Haviland 1977).

- categorical/thetic judgments and expectation (Kuroda 1972; Sasse 1987).

\section{Appendix B. Instruction types: English and Catalan instantiations}

(1) Link-focus sentences: typical topic-comment structures, predicate-focus structures (Lambrecht 1987, 1988), categorical judgments (Kuroda 1972; Sasse 1987).

a. The president $[F$ hates CHOCOLATE].

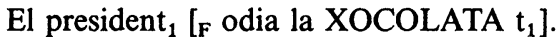

b. The president [F CALLED].

El president ${ }_{1}\left[{ }_{F}\right.$ ha TRUCAT $t_{1}$.

c. The president ${ }_{1}\left[\mathrm{~F}(\mathrm{I})\right.$ wouldn't BOTHER $\left.\mathrm{t}_{1}\right]$

El president $t_{1}\left[\mathrm{~F}\right.$ no l'EMPRENYARIA $\mathrm{t}_{1}$ pro].

(2) All-focus sentences: (a) neutral descriptions (Kuno 1972), news sentences (Schmerling 1976), sentence-focus structures (Lambrecht 1987, 1988), thetic judgments (Kuroda 1972; Sasse 1987); (b) there sentences; (c) predicatefocus sentences where the locus of update is inherited.

a. [F The PRESIDENT called].

[F Ha trucat el PRESIDENT].

b. [F There are protests in the STREETS].

[F Hi ha protestes als CARRERS]. 


\section{c. [F (He) HATES (it)]. \\ [F $\mathrm{L}_{2}{ }^{\prime} \mathrm{ODIA} \mathrm{e}_{2}$ pro].}

(3) Link-focus-tail and focus-tail sentences: narrow focus, constituent focus, typical open-proposition structures (Prince 1986).

a. The president ${ }_{F}$ HATES] chocolate.

El president ${ }_{1}\left[F l_{2}{\left.\text { 'ODIA } t_{2} t_{1},\right] \text { la xocolata }}_{2}\right.$.

b. The president hates [ $\mathrm{F}$ CHOCOLATE].

El president $\left[{ }_{F} t_{v}\right.$ la XOCOLATA $t_{1}$, odia $_{v}$.

Notes

* We are grateful to E. Hajičová, J. Hoeksema, H. de Hoop, L. Joosten, Y. Kıliçaslan, J. Miller, M. Vilkuna, A. Zaenen, and F. Zwarts for contributing data, comments, and/or suggestions to this paper. This research was supported by the Human Communication Research Centre, an interdisciplinary research center funded by the UK Economic and Social Research Council, and a British Academy/Leverhulme Senior Research Fellowship to the second author. Correspondence address: Enric Vallduví, Facultat de Traducció i Interpretació, Universitat Pompeu Fabra, La Rambla, 30-32, E-08002 Barcelona, Spain.

1. Question contextualization as a tool to identify the informational structure of the answer should be used with caution. These questions are meant to model a given context or information state, but sometimes the model is just an approximation. Questions like What's new? or What happened next? are often assumed not only to accept but also to require an all-focus answer (cf. Oehrle 1991). There is evidence, however, to argue that these questions are often followed by a VP-focus answer. Also, the most natural answer to the question What did she give to Harry? is not She gave a SHIRT to Harry but rather $A$ SHIRT. Assuming that the long answer is a normal answer here may obscure the reason behind the presence of an overt ground, its real task being unambiguously observable only in contexts in which an elliptical answer is ruled out (in Vallduvi 1992, for instance, these two answers are not informationally equivalent). In fact, most naturally occurring examples of sentences with a complex ground occur in contexts other than question-answer pairs.

2. Rochemont (1986) does not ignore the existence of sentences like (4). He argues, though, that they are a special case he calls "contrastive foci." In contrastive-focus sentences, what is not c-construable is the fact that the focal expression is the focus of the particular focus-ground partition it appears in. In other words, for Rochemont only contrastive foci are relationally new.

3. The Praguean approach (cf. Sgall et al. 1986) argues that only one articulation, ground-focus, is needed. This single articulation, however, is complemented by a notion of communicative dynamism. All sentence elements are ranked in a continuum of communicative dynamism. Instead of talking about a discrete partition between link and tail within the ground, Sgall et al. (1986) talk about ground elements with different degrees of dynamism (they push the communication forward to a larger or lesser degree). The discrete division of the ground into link and tail appears to be empirically sufficient to deal with languages like Catalan and English, with a relative freedom of linear order. It remains to be seen whether the same primitives can be successfully extended to Czech, a language with a more radical freedom of word order, which 
motivated the postulation of the more fine-grained dynamism continuum in the first place.

4. The notion of file card is historically related to Karttunen's (1976) discourse referent and is analogous to Webber's (1982) "coathooks" and Landman's (1986) "pegs." File cards mediate between referring expressions and real-world entities. Judging by the types of things NPs can refer to, file cards should be able to denote individuals, pluralities, substances, actions, event tokens, and event types, among other kinds (cf. Chierchia and McConnell-Ginet 1990: 50). Of course, the philosophical issue of what counts as an entity is still an open one.

5. The informational task of links as locus-of-update designators is totally independent of file-card management, which, as noted, is responsible for the activation and creation of file cards but has nothing to do with the update of their contents. The process of designating a file card as a locus of information entry is part of the general process of content update. There is, however, interesting interaction between the two dimensions. See Erteschik-Shir (1993).

6. Not every sentence type is amenable to an all-focus, thetic interpretation. Sasse (1987), for instance, mentions weather expressions, statements about body parts, unexpected events, and explanations as types of sentences that may encode thetic all-focus instructions. The "length" and "heaviness" of the predicate and its stage/individual nature are factors that have an effect as well.

7. A closer discussion of the dynamic instruction-based approach to information packaging is beyond the scope of this paper. The reader is referred to Vallduvi $(1992,1994 a)$ for further details.

8. Steedman's (1991) account has been slightly adapted for expository purposes. What Steedman states is that the "theme" portion of the sentence (i.e. the ground) is associated with an $\mathrm{L}+\mathrm{H}^{*} \mathrm{LH} \%$ tune. Looking at his examples, however, it is clear that the pitch accent in the "thematic" tune $\mathrm{L}+\mathrm{H}^{*}$ always falls on the subset of the ground that has been called link here.

9. Link contrast must be distinguished from focus contrast. In (i) italicized John is linkcontrastive and in (ii) capitalized John is focus-contrastive:

(i) John swept (and Mary mopped).

(ii) JOHN swept (not MARY).

While (ii) conversationally implicates that no relevant person other than John swept (hence the appropriate continuation not MARY), (i) implicates that someone else did something other than sweeping (hence the appropriate continuation and Mary mopped). In English the John phrases in (i) and (ii) are accented differently. In Catalan they are different in both their prosodic and their syntactic properties. Because of these interpretive and structural differences between links and foci, examples like (25a) cannot be considered examples of the configuration called "double focusing" or "complex focus" (see Krifka 1991-1992). For further discussion on the two types of contrast see Ronat (1979) and Szabolcsi (1981: 158).

10. In the case where John is a tail, the locus of update in (26) is inherited from context, be it a general situation file card or the denotation of she (in the latter case an additional account is needed of how "she," not explicit in [26], is inherited).

11. Detachment, especially right-detachment, occurs much less frequently in the written register than in oral registers. Within the latter, it is impressionistically more common in dialogue than in narrative.

12. In these examples and in examples below, detached phrases are coindexed with a trace in their base position and, if applicable, with the clitic they bind. Following (a some- 
what irregularly respected) Catalan orthographic convention, a comma is used to set off the right-detached phrases, but no punctuation is used with left-detachment.

13. Even though both readings are possible for (44b) (this can be checked by changing the gender or number of the huggee in [44a]), the reading where she refers to the subject in the previous sentence is favored when first reading the example. For a discussion of the factors that influence anaphora resolution in such cases see Stevenson et al. (1994).

The subject she in (b) would be considered a topic in a topic-comment articulation by most authors working within that framework. This is a place where the notion of link differs from the traditional notion of topic.

14. An anonymous reviewer points out that some speakers allow a VP-focus reading for (53) if an additional pitch accent appears on the direct object. Apparently, these speakers require an additional pitch accent on the indirect object in (49) as well.

15. Dutch contrastive dislocation must not be identified with Dutch left-dislocation. In left-dislocation the dislocated phrase binds a pronominal as well. This prominal, however, does not appear in a lefthand slot but rather in situ. In contrastive dislocation, the detached phrase is felt to be part of the clause (for instance, it displays connectivity effects), much as in Catalan left-detachment and English topicalization. The dislocated phrase in left-dislocation behaves as if external to the clause, as in Catalan and English hanging left-dislocation.

16. Received wisdom, going back to Bresnan (1971), is that configurations like (i) and (ii) are analogous to (66b) in that the postaccent argument cannot be focal and, therefore, that a VP-focus is disallowed:

(i) I passed a GLASS to Susie.

(ii) He mailed a LETTER to his wife.

Some analyses, however, like Drubig (1994), assume that these configurations are possible and that, therefore, English VPs also have the ability to display focus projection to the right (see Vallduvi and Zacharski 1994 for some discussion on structures analogous to these). Also, Vallduví and Vilkuna (1995) and Kiss (i.p.) point out that the realization of focus in Hungarian may be more complex than so far believed. If one made the conceptual distinctions these yet-to-be-published papers suggest, the analysis of focus realization in Hungarian discussed above would have to be somewhat modified. As a consequence of these modifications, Hungarian VPs would have both rightward and leftward focus projection.

17. We will ignore the fact that nominative objects must necessarily appear immediately to the left of the verb. These behave syntactically and semantically like incorporated elements. As a result, the preverbal slot is the slot immediately to the left of the sequence formed by the verb and the nominative object.

18. Erguvanl 1984 identifies three "pragmatic functions" in the Turkish sentence: topic, focus, and backgrounded information. These three notions appear to be akin to the three informational primitives - link, focus, and tail, respectively - that we have been utilizing here. Erguvanl claims that prefocal tails are different from backgrounded information in that they are neutral with respect to pragmatic function. She argues that pragmatic function in Turkish is linearized in the following way: topic-neutral-focusV-background. Nothing is said about the intonational strategy discussed above, where foci may precede ground material.

19. The speaker who provided these sentences speculated that the reason for his preference was that in Dutch a contrastive link best precedes the focus. Hence the use of detachment in (91c) and the use of prosody in (90c). 
20. Since the string order in the Catalan NP is noun-adjective, the English example has been slightly changed to make the default phrase-final element, i.e. the adjective, the potentially deaccentable item.

\section{References}

Adams, Marianne (1987). From Old French to the theory of pro-drop. Natural Language and Linguistic Theory 5, 1-32.

Akmajian, Adrian (1979 [1970]). Aspects of the Grammar of Focus in English. New York: Garland.

Ammann, H. (1969 [1928]). Die menschliche Rede 2. (Der Satz), 3rd ed. Darmstadt: Lahr.

Andersson, Lars-Gunnar (1974). Topicalization and Relative Clause Formation. Gothenburg Paper in Theoretical Linguistics 25. Gothenburg: Göteborg Universitet.

Ariel, Mira (1988). Referring and accessibility. Journal of Linguistics 24, 67-87.

Bardovi-Harlig, Kathleen (1983). On the claim that topics are not stressed. CLS (Parasession) 19, 17-27.

Bland, Susan (1980). Topic/comment sentences in English. Cornell Working Papers in Linguistics 2, 32-49.

Bonet, Eulàlia (1990). Subjects in Catalan. MIT Working Papers in Linguistics (Papers on Wh-movement) 13, 1-26.

Bresnan, Joan (1971). Sentence stress and syntactic transformations. Language 47, 257-281.

Brody, Michael (1990). Some remarks on the focus field in Hungarian. University College London Working Papers in Linguistics 2, 201--225.

Brown, Gillian; and Yule, George (1983). Discourse Analysis. Cambridge: Cambridge University Press.

Chafe, Wallace L. (1976). Givenness, contrastiveness, definiteness, subjects, topics, and point of view. In Subject and Topic, Charles N. Li (ed.), 25-55. New York: Academic Press.

Chierchia, Gennaro; and McConnell-Ginet, Sally (1990) Meaning and Grammar. Cambridge, MA: MIT Press.

Chomsky, Noam (1971). Deep structure, surface structure, and semantic interpretation. In Semantics, Daniel Steinberg and Leon Jacobovits (eds.), 183-216. Cambridge: Cambridge University Press.

Clark, Herbert H.; and Haviland, Susan E. (1977). Comprehension and the given-new contract. In Discourse Production and Comprehension, Roy O. Freedle (ed.), 1-40. Hillsdale, NJ: Erlbaum.

Cohen, Antonie; and 't Hart, Johan (1967). On the anatomy of intonation. Lingua 19, 177-192.

Contreras, Heles (1976). A Theory of Word Order with Special Reference to Spanish. Amsterdam: North-Holland.

-(1991). On the position of subjects. In Perspectives on Phrase Structure: Heads and Licensing, Susan D. Rothstein (ed.), 63-79. Syntax and Semantics 25. New York: Academic Press.

Culicover, Peter; and Rochemont, Michael S. (1983). Stress and focus in English. Language $59,123-165$.

Dahl, Östen (1974). Topic-comment structure revisited. In Topic and Comment, Contextual Boundedness and Focus, Östen Dahl (ed.), 1-24. Papers in Text Linguistics 6. Hamburg: Buske. 
-(1976). What is new information? In Reports on Text Linguistics: Approaches to Word Order, Nils E. Enkvist and Viljo Kohonen (eds.), 37-50. Åbo: Åbo Akademi.

Daneš, František (1968 [1957]). Some thoughts on the semantic structure of the sentence. Lingua 21, 55-69.

Davison, Alice (1984). Syntactic markedness and the definition of sentence topic. Language $60,797-846$.

de Hoop, Helen (1992). Case configuration and noun phrase interpretation. Unpublished Ph.D. dissertation, Rijksuniversiteit Groningen.

Delin, Judy (1989). Cleft constructions in English discourse. Unpublished Ph.D. dissertation, University of Edinburgh.

-(1992). Properties of it-cleft presupposition. Journal of Semantics 9, 289-306.

-(1995). Presupposition and shared knowledge in it-clefts. Language and Cognitive Processes 10, 97-120.

Diesing, Molly (1992). Indefinites. Cambridge, MA: MIT Press.

Drubig, H. Bernhard (1994). Island Constraints and the Syntactic Nature of Focus and Association with Focus. Arbeitspapiere des Sfb 340 43. Tübingen: Universität Tübingen.

Enç, Murvet (1991). The semantics of specificity. Linguistic Inquiry 22, 1-25.

Erguvanl, Eser E. (1984). The Function of Word Order in Turkish Grammar. Berkeley: University of California Press.

Erteschik-Shir, Nomi (1973). On the nature of island constraints. Unpublished Ph.D. dissertation, MIT.

-(1979). Discourse constraints on dative movements. In Discourse and Syntax, Talmy Givón (ed.), 441-467. Syntax and Semantics 12. New York: Academic Press.

-(1986). Wh-questions and Focus. Linguistics and Philosophy 9, 117-149.

- (1993). The dynamics of focus structure. Unpublished manuscript. Ben Gurion University of the Negev, Be'er-Sheva.

-; and Lappin, Shalom (1979). Dominance and the functional explanation of island phenomena. Theoretical Linguistics 6, 41-85.

--; and Lappin, Shalom (1983). Under stress: a functional explanation of English sentence stress. Journal of Linguistics 19, 419-453.

Fernández-Soriano, Olga (1989). Strong pronouns in null-subject languages and the Avoid Pronoun Principle. MIT Working Papers in Linguistics (SCIL I) 11, 228-239.

Féry, Caroline (1992). Focus, Topic and Intonation in German. Technical Report 20, Sonderforschungsbereich 340 . Tübingen: Universität Tübingen.

Firbas, Jan (1964). On defining the theme in functional sentence perspective. Travaux linguistiques de Prague 1, 267-280.

-(1971). On the concept of communicative dynamism in the theory of Functional Sentence Perspective. Brno Studies in English 7, 12-47.

- (1975). On the thematic and the non-thematic section of the sentence. In Style and Text: Studies Presented to Nils Erik Enkvist, Hakan Ringbom et al. (eds.), 314-334. Stockholm: Skriptor.

Garrod, Simon; and Sanford, Anthony J. (1982). The mental representation of discourse in a focussed memory system: implications for the interpretation of anaphoric noun phrases. Journal of Semantics 1, 21-41.

Givón, Talmy (1983). Introduction. In Topic Continuity in Discourse, Talmy Givón (ed.), 5-41. Amsterdam and Philadelphia: Benjamins.

-(1992). The grammar of referential coherence as mental processing instructions. Linguistics 30, 5-55.

Grosz, Barbara (1981). Focusing and description in natural dialogues. In Elements of Discourse Understanding, Aravind K. Joshi, Bonnie L. Webber, and Ivan Sag (eds.), 84-105. Cambridge: Cambridge University Press. 
Gundel, Jeanette K. (1974). The role of topic and comment in linguistic theory. Unpublished $\mathrm{Ph} . \mathrm{D}$. dissertation, University of Texas, Austin.

- (1988). Universals of topic-comment structure. In Studies in Syntatic Typology, Michael Hammond, Edith Moravcsik, and Jessica R. Wirth (eds.), 209-239. Amsterdam and Philadelphia: Benjamins.

-(1994). On the different kinds of focus. In Focus and Natural Language Processing, vol. 3 , Peter Bosch and Rob A. van der Sandt (eds.), 457-466. IBM Working Papers of the Institute for Logic and Linguistics 8. Heidelberg: IBM Deutschland.

-; Hedberg, Nancy; and Zacharski, Ron (1993). Cognitive status and the form of referring expressions. Language 69, 274-307.

Hajičová, Eva (1984). Topic and focus. In Contributions to Functional Syntax: Semantics and Language Comprehension, Petr Sgall (ed.), 189-202. LLSEE 16. Amsterdam and Philadelphia: Benjamins.

-(1987). Focussing - a meeting point of linguistics and artificial intelligence. In Artificial Intelligence II, Philippe Jorrand and V. Sgurev (eds.), 311-321. Amsterdam: Elsevier.

Halliday, Michael A. K. (1967). Notes on transitivity and theme in English, part II. Journal of Linguistics 3, 199-244.

-(1985). An Introduction to Functional Grammar. London: Arnold.

Hannay, Michael (1991). Pragmatic function assignment and word order variation in a functional grammar of English. Journal of Pragmatics 16, 131-155.

Heim, Irene (1982). The semantics of definite and indefinite noun phrases. Unpublished Ph.D. dissertation, University of Massachusetts, Amherst.

Hockett, Charles F. (1958). A Course in Modern Linguistics. New York: Macmillan.

Hoffman, Beryl (1994). Generating context-appropriate word orders in Turkish. International Workshop on Natural Language Generation 7, 117-126.

Horvath, Julia (1986). FOCUS in the Theory of Grammar and the Syntax of Hungarian. Dordrecht: Foris.

Humphreys, Kevin (1993). Given and new information: a terminological minefield. Unpublished manuscript, University of Edinburgh.

Jackendoff, Ray (1972). Semantic Interpretation in Generative Grammar. Cambridge, MA: MIT Press.

Jacobs, Joachim (1984). Funktionale Satzperspektive und Illokutionssemantik. Linguistische Berichte 91, 25-58.

Karttunen, Lauri (1976). Discourse referents. In Notes from the Linguistic Underground, James D. McCawley (ed.), 363-385. Syntax and Semantics. New York: Academic Press.

Kulçaslan, Yilmaz (1994). Information packaging in Turkish. Unpublished M.Sc. dissertation, University of Edinburgh.

Kiss, Katalin É. (1981). Structural relations in Hungarian, a "free" word order language. Linguistic Inquiry 12, 185-213.

-(1986). The order and scope of operators in the Hungarian sentence. In Topic, Focus, and Configurationality, Werner Abraham and Sjaak de Meij (eds.), 181-214. Amsterdam and Philadelphia: Benjamins.

-(i.p.). Focus as a non-uniform phenomenon. In Proceedings of the Göttingen Focus Workshop, Inga Kolkhof, Susanne Winkler, and H. Bernhard Drubig (eds.). Arbeitspapiere des Sfb 340 69. Tübingen: Universität Tübingen.

Komlósy, András (1986). Focussing on focus in Hungarian. In Topic, Focus, and Configurationality, Werner Abraham and Sjaak de Meij (eds.), 215-226. Amsterdam and Philadelphia: Benjamins.

Krifka, Manfred (1991-1992). A compositional semantics for multiple focus constructions. Linguistische Berichte, Suppl. 4, 17-53. 
Kuno, Susumu (1972). Functional sentence perspective. Linguistic Inquiry 3, 269-320.

Kuroda, Shige-Yuki (1972). The categorical and the thetic judgment: evidence from Japanese syntax. Foundations of Language 9, 153-185.

Lakoff, George (1971). On generative semantics. In Semantics, Daniel Steinberg and Leon Jacobovits (eds.), 232-296. Cambridge: Cambridge University Press.

Lambrecht, Knud (1987). Sentence focus, information structure, and the thetic-categorical distinction. $B L S 13,366-382$.

-(1988). When subjects behave like objects: a markedness analysis of sentence focus constructions across languages. Unpublished manuscript, University of Texas, Austin.

Landman, Fred (1986). Pegs and alecs. In Towards a Theory of Information, 97-155. Dordrecht: Foris.

Li, Charles N.; and Thompson, Sandra A. (1976). Subject and topic: a new typology of language. In Subject and Topic, Charles N. Li (ed.), 457-589. New York: Academic Press.

Mathesius, Vilém (1915). O passivu v moderní angličtině. Sborník filologický 5, 198-220.

Oehrle, Richard T. (1991). Prosodic constraints on dynamic grammatical analysis. Edinburgh Working Papers in Cognitive Science 7, 167-195.

Pesetsky, David (1987). Wh-in-situ: movement and unselective binding. In The Representation of (In) Definiteness, Eric Reuland and Alice ter Meulen (eds.), 98-129. Cambridge, MA: MIT Press.

Pierrehumbert, Janet B. (1980). The phonology and phonetics of English intonation. Unpublished Ph.D. dissertation, MIT.

Prince, Ellen F. (1978). A comparison of wh-clefts and it-clefts in discourse. Language 54, 883-906.

-(1981). Topicalization, focus-movement, and Yiddish-movement: a pragmatic differentiation. $B L S 7,249-264$.

-(1984). Topicalization and left-dislocation: a functional analysis. In Discourses in Reading and Linguistics, Sheila J. White and Virginia Teller (eds.), 213-225. Annals of the New York Academy of Sciences 433. New York: Academy of Sciences.

-(1986). On the syntactic marking of presupposed open propositions. CLS (Parasession) 22, 208-222.

Puskás, Genoveva (1992). The wh-criterion in Hungarian. Unpublished manuscript, Université de Genève.

Reinhart, Tanya (1982). Pragmatics and linguistics: an analysis of sentence topics. Philosophica 27, 53-94.

Rigau, Gemma (1988). Strong pronouns. Linguistic Inquiry 19, 503-511.

Rochemont, Michael S. (1978). A Theory of Stylistic Rules in English. New York: Garland.

- (1986). Focus in Generative Grammar. Amsterdam and Philadelphia: Benjamins.

Ronat, Mitsou (1979). Pronoms topiques et pronoms distinctifs. Langue Française 44, $106-128$.

Rosselló, Joana (1986). Gramàtica, configuracions i referència: per una teoria alternativa del pro-drop románic. Unpublished Ph.D. dissertation, Universitat de Barcelona.

Sasse, Hans-Jurgen (1987). The thetic/categorical distinction revisited. Linguistics 25, 511-580.

Schauber, Ellen (1978). Focus and presupposition: a comparison of English intonation and Navajo particle placement. In Elements of Tone, Stress, and Intonation, Donna J. Napoli (ed.), 144-173. Washington, D.C.: Georgetown University Press.

Schlobinski, Peter; and Schutze-Coburn, Stephan (1992). On the topic of topic and topic continuity. Linguistics 30, 89-121.

Schmerling, Susan F. (1976). Aspects of English Sentence Stress. Austin: University of Texas Press. 
Selkirk, Elisabeth O. (1984). Phonology and Syntax. Cambridge, MA: MIT Press.

Sgall, Petr; and Hajičová, Eva (1977). Focus on focus. Prague Bulletin of Mathematical Linguistics 28, 5-51.

-; and Hajičová, Eva (1978). Focus on focus. Prague Bulletin of Mathematical Linguistics 29, 23-41.

-; Hajičová, Eva; and Panevová, Jarmila (1986). The Meaning of the Sentence in its Semantic and Pragmatic Aspects. Dordrecht: Reidel.

Sidner, Candace L. (1981). Focusing for interpretation of pronouns. American Journal for Computational Linguistics 7, 217-231.

Solà, Jaume (1992). Agreement and subjects. Unpublished Ph.D. dissertation, Universitat Autònoma de Barcelona, Barcelona.

Stalnaker, Robert (1978). Assertion. In Pragmatics, Peter Cole (ed.), 315-332. Syntax and Semantics 9. New York: Academic Press.

Steedman, Mark (1991). Structure and intonation. Language 67, 260-296.

Stevenson, Rosemary J.; Crawley, Rosalind A.; and Kleinman, David (1994). Thematic roles, focus and the representation of events. Language and Cognitive Processes 10, 333-354.

Strawson, Peter F. (1964). Identifying reference and truth-values. In Semantics, Daniel Steinberg and Leon Jacobovits (eds.), 86-99. Cambridge: Cambridge University Press.

Szabolcsi, Anna (1981). The semantics of topic-focus articulation. In Formal Methods in the Study of Language, Theo M. V. Jannsen and Martin B. J. Stokhof (eds.), 513-540. Amsterdam: Mathematisch Centrum.

Thwing, Rhonda; and Watters, John (1987). Focus in Vute. Journal of African Languages and Linguistics 9, 95-121.

Välimaa-Blum, Riitta (1988). Finnish existential clauses: their syntax, pragmatics and intonation. Unpublished Ph.D. dissertation, Ohio State University, Columbus.

Vallduví, Enric (1992). The Informational Component. New York: Garland.

-(1993a). Catalan as VOS: Evidence from information packaging. In Linguistic Perspectives in the Romance Languages, William J. Ashby, Marianne Mithun, Giorgio Perissinotto, and Eduardo Raposo (eds.), 335-350. Amsterdam and Philadelphia: Benjamins.

-(1993b). A preverbal landing site for quantificational operators. Catalan Working Papers in Linguistics 2, 319-343.

-(1994a). The dynamics of information packaging. In Integrating Information Structure into Constraint-Based and Categorial Approaches, Elisabet Engdahl (ed.), 1-26. DYANA-2 Report R1.3.B. Amsterdam: ILLC.

-(1994b). Detachment in Catalan and information packaging. Journal of Pragmatics 22, 573-601.

-; and Engdahl, Elisabet (1995). Information packaging and grammar architecture. NELS 25, 519-533.

-; and Vilkuna, Maria (1995). Focus and contrast in information structure: Finnish and Catalan. Paper presented at the 18th GLOW Colloquium, University of Tromsoe, Tromsoe.

-; and Zacharski, Ron (1994). Accenting phenomena, association with focus, and the recursiveness of focus-ground. In Proceedings of the Ninth Amsterdam Colloquium, P. Dekker and M. Stokhof (eds.), 683-702. Amsterdam: ILLC.

van Deemter, Kees (1994). What's new? A semantic perspective on sentence accent. Journal of Semantics 11, 1-31.

van der Sandt, Rob A. (1988). Context and Presupposition. London: Croom Helm. 
von Stechow, Arnim (1981). Topic, focus and local relevance. In Crossing the Boundaries in Linguistics, Wolfgang Klein and Willem J. M. Levelt (eds.), 95-130. Dordrecht: Reidel.

Ward, Gregory L. (1988). The Semantics and Pragmatics of Preposing. New York: Garland. Webber, Bonnie L. (1982). So what can we talk about now? In Computational Models of Discourse, Michael Brady and Robert C. Berwick (eds.), 331-371. Cambridge, MA: MIT Press.

Williams, Edwin (1981). Remarks on stress and anaphora. Journal of Linguistic Research $1,1-16$.

Wilson, Deirdre; and Sperber, Dan (1979). Ordered entailments: an alternative to presuppositional theories. In Presupposition, Choon-Kyu Oh and David A. Dinneen (eds.), 299-323. Syntax and Semantics. New York: Academic Press.

Zaenen, Annie (1984). Contrastive dislocation in Dutch and Icelandic. Unpublished manuscript, Cornell University, Ithaca. 
Brought to you by | De Gruyter / TCS Authenticated

Download Date | 1/23/18 8:58 AM 